\title{
Binuclear Non-heme Iron Catalysts
}

John P. Caradonna, Department of Chemistry, Yale University

DOE grant number: DE-FG02-92ER14279

Dates: August 1, 1992 - July 31, 1999

This project involved the investigation of the ability of non-heme iron metalloenzyme reactivity model complexes to catalyze the oxidation of alkane and arene molecules. The objectives were to synthesize a series of non-heme mononuclear and dinuclear iron complexes, characterize their electronic structure and reactivity properties, characterize intermediates formed during oxygen atom transfer chemistry, and elucidate the mechanisms and specificity of the reactions. These data also were to be compared to analogous heme-based chemistry.

A series of diferrous, ferrous/ferric, and diferric complexes were synthesized from simple polyamide and polycarboxylate ligands and characterized by visible absorption, EPR and IR spectroscopy and by cyclic voltametry. The diferrous compounds, which are all powerful reductants, heterolytically decompose peracids and are capable of acting as oxygen atom transfer catalysts when reacted with oxygen atom donor compounds and simple olefins, yielding both allylic oxidation and epoxidation products. Lowtemperature optical spectroscopic studies provide evidence in support of an $\mathrm{Fe}(\mathrm{IV})=\mathrm{O}$ intermediate, rather than an O-donor adduct, as the reactive species. An isostructural dicobalt(II) complex gives rise only to epoxidation products. These reactivity studies provide important new information of the chemistry of dinuclear nonheme iron systems.

Publications resulting from this project:

1. " $\mathrm{Fe}^{2+}$-catalyzed heterolytic $\mathrm{RO}-\mathrm{OH}$ bond cleavage and substrate oxidation: $\mathrm{A}$ functional synthetic non-heme iron monooxygenase system", Foster TL, Caradonna JP (2003) J. Am. Chem. Soc. 125: 3678-3679.

2. "Skirting the oxo-wall: characterization and catalytic reactivity of binuclear $\mathrm{Co}^{2+/ 3+}$ 1,2-bis(2-hydroxybenzamido)benzene complexes with comparison to their isostructural $\mathrm{Fe}^{2+/ 3+}$ analogs. Implications of d-electron count on oxygen atom transfer catalysis", Mukerjee S, Skogerson K, DeGala S, Caradonna JP (2000) Inorg. Chim. Acta 297: 313-329.

3. "Iodosylbenzene oxidation of alkanes, alkenes, and sulfides catalyzed by binuclear non-heme iron systems: Comparison of non-heme iron versus heme iron oxidation pathways", Mukerjee S, Stassinopoulos A, Caradonna JP (1997) J. Am. Chem. Soc. 119: 8097-8098.

4. "Reactivity models for dinuclear iron metalloenzymes - Oxygen atom transfer catalysis and dioxygen activation", Stassinopoulos A, Mukerjee S, Caradonna JP (1995) Adv. Chem. Ser. 246: 83-120.

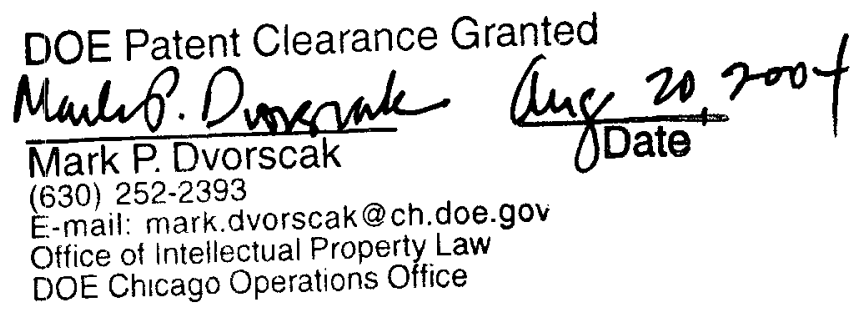




\section{DISCLAIMER}

This report was prepared as an account of work sponsored by an agency of the United States Government. Neither the United States Goverameat nor any agency thereof, nor any of their employees, makes any warranty, express or implied, or assumes any legal liability or responsibility for the accuracy, completeness, or usefulness of any information, apparatus, product, or process disclosed, or represents that its use would not infringe privately owned rights. Reference berein to any specific commercial product, process, or service by trade name, trademark, manufacturet, or otherwise does not necessarily constitute or imply its endorsement, recommendation, or favoring by the United States Government or any agency thereof. The views and opinions of authors expressed herein do not necessarily state or reflect those of the United States Government or any agency thereof. 


\section{DISCLAIMER}

Portions of this document may be illegible in electronic image products. Images are produced from the best available original document. 
Iodosylbenzene Oxidation of Alkanes, Alkenes, and Sulfides Catalyzed by Binuclear Non-heme Iron Systems: Comparison of Non-heme Iron Versus Heme Iron Oxidation Pathways

Subhasish Mukerjee, Adonis Stassinopoulos, and John P. Caradonna*

\section{Department of Chemistry, Kline Laboratory Yale University, P.O. Box 208107 New Haven, Connecticut 06520-8107}

Received March 25, 1997

Understanding the mechanisms by which binuclear non-heme iron centers such as those found in the active site of methane monooxygenase (MMO) can act as oxygen atom transfer catalysts remains a serious and complex challenge. ${ }^{1,2}$ Despite recent major advances in our understanding of the structural, ${ }^{3}$ spectroscopic, 4,5 and mechanistic aspects of enzymatic alkane oxidation, ${ }^{4,5}$ attempts to model biological hydrocarbon oxidation are less well developed. ${ }^{12}$ While synthetic non-heme diferric systems are reported to oxygenate substrates in the presence of either dioxygen ${ }^{6}$ or alkyl peroxides, ${ }^{1,2,4,5,7-13}$ the peroxide chemistry is now thought to be dominated by oxygen-based free radical pathways. ${ }^{14-17}$. In our continuing efforts to develop catalytically competent binuclear non-heme Fe complexes that can perform biologically relevant oxo-atom transfer chemistry, ${ }^{18,19}$ we report herein the remarkable reactivity properties of $\left[\mathrm{Fe}_{2}{ }^{2+}\left(\mathrm{H}_{2} \mathrm{Hbamb}\right)_{2}(\mathrm{~N} \text {-MeIm })_{2}\right](1, \text { Scheme } 1)^{20 a}$ as well as those of its mixed-valence $\left[\mathrm{Fe}^{2+}, \mathrm{Fe}^{3+}\right](2)$ and diferric $\left[\mathrm{Fe}^{3+}\right.$, $\mathrm{Fe}^{3+}$ ] (3) states. We find that both 1 and 2 are uniquely capable of catalyzing the oxidation of alkanes, alkenes, and sulfides by the known oxygen atom donor, OIPh. The catalytic chemistry of non-heme 1 and 2 parallel that reported for cytochrome P-450, a system believed to involve a porphyrin cation radical $\left[\mathrm{Fe}^{4+}=0\right]$ reactive intermediate. ${ }^{21-23}$

* Corresponding author. E-mail: john.caradonna@yale.edu.

(1) Caradonna, J. P.; Stassinopoulos, A. Adv. Inorg. Biochem. 1994, 9, 245-315.

(2) Stassinopoulos, A.; Mukerjee, S.: Caradonna, J. P. Reactivity Models for Dinuclear Iron Metalloenzymes: Oxygen Atom Transfr Catalysis and Dioxygen Activation; Stassinopoulos, A., Mukerjee, S., Caradonna, J. P. Eds.; American Chemical Society: Washington D.C., 1994; Vol. 246, pp 83-120.

(3) Rosenzweig, A. C.; Frederick, C. A.; Lippard, S. J.; Nordlund, P. Nature 1993, 366, 537-43.

(4) Feig, A. L.; Lippard, S. J. Chem. Rev. 1994, 94, 759-805.

(5) Waller, B. J.; Lipscomb, J. D. Chem. Rev. 1996, 96, 2625-2658.

(6) Rosenzweig, A. C.; Feng, X.; Lippard, S. J. Applications of Enzyme

Biotechnology; Kelly, J. W., Baldwin. T. O., Eds.; Plenum Press: New

York, 1991; pp 69-85.

(7) Barton, D. H. R.; Beck, A. H.; Taylor, D. K. Tetrahedron 1995, 5I, $5245-5254$.

(8) Vincent, J. M. Menage, S; Lambeaux, C.; Fontecave, M. Tetrahedron Lett. 1994, 35, 6287-6290.

(9) Kim, J.; Harrison, R. G.; Kim, C.; Que, L. J. J. Am. Chem. Soc. 1996, 118, 4373-4379.

(10) Perkins, M. J. Chem. Soc. Rev. 1996, 25, 229-236

(11) Minisci, F.; Fontana, F.; Araneo, S.; Recupero, F.; Zhao, L. SynLett 1996, 119-125.

(12) Arends, I. W. C. E.; Ingold, K. U.; Wayner, D. D. M. J. Am. Chem. Soc. 1995, $117,4710-4711$

(13) Stassinopoulos, A.; Caradonna, J. P. J. Am. Chem. Soc. 1990, I12, $7071-7073$.

(14) Stassinopoulos, A.; Schulte, G.; Papaefthymiou, G. C.; Caradonna,

J. P. J. Am. Chem. Soc. 1991, 113, 8686-8697.

(15) Abbreviations: H4Hbamb, 2,3-bis(2-hydroxybenzamido)-2,3-dimethylbutane; $N$-MeIm, $N$-methylimidazole; $\mathrm{H}_{4} \mathrm{Hbab}, 1,2$-bis(2-hydroxybenzamido)benzene; PPAA, phenylperacetic acid; TPP, tetraphenylporphyrin. (16) McMurry, T. J.; Groves, J. T. Cyt P450 model systems; McMurry, T. J., Groves, J. T., Eds.; Plenum Press: New York, 1986; pp 1-28.

(17) Sono, M.; Poach, M. P.; Coulter, E. D.; Dawson, J. H. HemeContaining Oxidases; Sono, M., Poach, M. P. Coulter, E. D., Dawson, J H., Eds.; American Chemical Society: Washington, D.C., 1996; Vol. 96, pp 2841-2888.

(18) Anson, F. C.; Christie, J. A.; Collins, T. J.; Coots, R. J.; Furutani, T. T.; Gipson, S. L.; Keech, J. T.; Kraft, T. E.; Santasiero, B. D.; Spies, G. H. J. Am. Chem. Soc. 1984, 106, 4460-4472.
Scheme 1
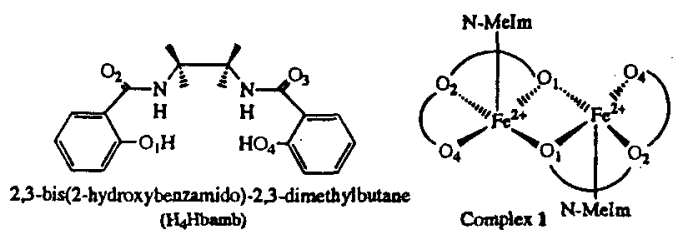

The reaction of equimolar quantities of trans- $\mathrm{Fe}^{2+}(\mathrm{N} \text {-Melm })_{2}$ $(\mathrm{Cl})_{2}(\mathrm{MeOH})_{2}{ }^{18,19}$ and the dilithium salt of 2,3-bis(2-hydroxybenzamido)-2,3-dimethylbutane, $\mathrm{H}_{4}$ bamb (Scheme 1), ${ }^{24}$ in anhydrous $1 \%$ methanol-acetonitrile under anaerobic conditions afforded $\left[\mathrm{Fe}_{2}{ }^{2+}\left(\mathrm{H}_{2} \text { bamb }\right)_{2}(\mathrm{~N} \text {-MeIm})_{2}\right](1)^{25 a}$ (60\% yield). Isothermal distillation techniques ${ }^{18}$ indicate that 1 has a molecular weight of $\approx 1100$, consistent with its dimeric formulation. EPR spectra of 1 show a $g_{\text {eff }} \approx 16$ signal, suggesting a ferromagnetically coupled $S=4$ core as previously reported for an analogous binuclear system. ${ }^{19}$ Cyclic voltammetry experiments show two coupled $1 \mathrm{e}^{-}$oxidation/reduction processes; a scanrate-dependent quasi-reversible process at $-310 \mathrm{mV}$ (NHE) and an electrochemically reversible couple at $-690 \mathrm{mV}$ (NHE), giving $K_{\text {com }}=2.7 \times 10^{6}$. Repetitive scans showed no significant decrease in either cathodic or anodic current; ligand centered redox behavior was observed outside this region of interest. The scan-rate dependence of $\Delta E_{\mathrm{p}}$, attributed to kinetic effects, allowed the measurement of an intrinsic rate constant, $k=2 \times 10^{-5}$, assuming pseudo-first-order kinetics. This rate constant, thought to reflect a structural change, is independent of [1] over a 3 -fold range. A similar process was demonstrated in the redox transformation $(-10$ and $-260 \mathrm{mV})$ of $\left[\mathrm{Fe}_{2}{ }^{2+}\left(\mathrm{H}_{2}-\right.\right.$ $\left.\mathrm{Hbab})_{2}(\mathrm{~N} \text {-MeIm })_{2}\right]^{19}$ The stoichiometric $\mathrm{I}_{2}$ titration of 1 , as monitored by UV/vis spectroscopy, shows the clean formation of $\left[\mathrm{Fe}^{2+}, \mathrm{Fe}^{3+}\right](2)$ (isosbestic point at $325 \mathrm{~nm}$ ); the titration of one additional oxidizing equivalent readily converts 2 to $\left[\mathrm{Fe}^{3+}\right.$, $\left.\mathrm{Fe}^{3+}\right]$ (3) (isosbestic points at 457 and $335 \mathrm{~nm}$ ). Solution molecular weight characterizations of 2 and 3 are consistent

(19) (a) $\left[\mathrm{Fe}_{2}{ }^{2+}\left(\mathrm{H}_{2} \text { bamb }\right)_{2}(\mathrm{~N}-\mathrm{Melm})_{2}\right]$ solvated (1): Anal. Calcd for $\mathrm{C}_{55-}$ $\mathrm{H}_{72} \mathrm{~N}_{9} \mathrm{O}_{13} \mathrm{Fe}_{2}: \mathrm{C}_{7} 55.90 ; \mathrm{H}, 6.10 ; \mathrm{N}, 10.68 ; \mathrm{Fe}, 9.49$. Found: $\mathrm{C}, 55.69 ; \mathrm{H}$ $5.70 ; \mathrm{N}, 10.86 ; \mathrm{Fe}, 9.43$. UV/vis (DMF): $\lambda_{\max }\left(\epsilon_{M}\right) 314 \mathrm{~nm}(20000)$. IR: $v_{\text {maideNH }}=3430 \mathrm{~cm}^{-1}, v_{\text {amideco }}=1611 \mathrm{~cm}^{-1}$. Electrochemistry (NHE): quasi reversible redox process, $-690 \mathrm{mV}, \Delta E=220-470 \mathrm{mV}$ with scan rate $25-125 \mathrm{mV} \mathrm{s}^{-1}$; reversible process, $-310 \mathrm{mV}, \Delta E=70 \mathrm{mV}$. (b) rate $25-125 \mathrm{mV} \mathrm{s}^{-1}$; reversible process, $-310 \mathrm{mV}, \Delta E=70 \mathrm{mV}$. (b)
$\left.\left[\mathrm{Fe}^{2+} \mathrm{Fe}^{3+}\left(\mathrm{H}_{2} \text { bamb }\right)_{2}(\mathrm{~N} \text {-Melm })_{2}\right] \mathrm{I}^{-}\right)$solvated (2): Anal. Calcd. for $\mathrm{C}_{55} \mathrm{H}_{72}-$ $\left[\mathrm{Fe}^{2+} \mathrm{Fe}^{3+}\left(\mathrm{H}_{2} \mathrm{bamb}\right)_{2}(\mathrm{~N}-\mathrm{MeIm})_{2}\right]\left(\mathrm{I}^{-}\right)$solvated (2): Anal. Calcd. for $\mathrm{C}_{55} \mathrm{H}_{72-}-$
$\mathrm{N}_{10} \mathrm{O}_{15} \mathrm{ICl} \mathrm{F}_{2} \mathrm{Fe}_{2}: \mathrm{C}, 49.18 ; \mathrm{H}, 5.36 ; \mathrm{N}, 10.43 ; \mathrm{Fe}, 8.31$. Found: C, 48.67, $\mathrm{H}, 5.27 ; \mathrm{N}, 10.37 ; \mathrm{Fe}, 8.10$. UV/vis (DMF): $\lambda_{\max }\left(\epsilon_{\mathrm{M}}\right) 301 \mathrm{~nm}(25000)$, $436 \mathrm{~nm}(7000)$. IR: $v_{\text {mideNH }}=3430 \mathrm{~cm}^{-1} ; v_{\operatorname{madid} 00}=1654 \mathrm{~cm}^{-1}$. EPR: $g_{\text {eff }}=4.3$. (c) $\left[\mathrm{Fe}_{2}{ }^{3+}\left(\mathrm{H}_{2} \text { bamb }\right)_{2}(\mathrm{~N}-\mathrm{Melm})_{2}\right]\left(\mathrm{I}^{-}\right)_{2}$ solvated (3): Anal. Calcd for $\mathrm{C}_{53} \mathrm{H}_{72} \mathrm{~N}_{10} \mathrm{O}_{15} \mathrm{I}_{2} \mathrm{Cl}_{2} \mathrm{Fe}_{2}$ : C, $44.90, \mathrm{H}, 4.90, \mathrm{~N}, 9.53, \mathrm{Fe}, 7.60$. Found: $\mathrm{C}$ 44.22, H, 5.20, N, 9.71; Fe, 7.46. UV/vis (DMF): $\lambda_{\max }\left(\epsilon_{M}\right)=301 \mathrm{~nm}$ $(25000), 470 \mathrm{~nm}(7000)$. IR: $v_{\text {anideNH }}=3430 \mathrm{~cm}^{-1}, v_{\text {amideco }}=1654 \mathrm{~cm}^{-1}$. Forms adduct with catechol DMF $\left(\lambda_{\max }=560 \mathrm{~nm}\right)$.

(20) All gas chromatographic analysis were performed on a HewlettPackard Series 2 GC equipped with a methylsilicon capillary column and interfaced to a HP3396 series II integrator. Mass spectral analyses were performed on a HP 5971 mass-selective detector attached to a HP5890 Series 2 GC. Authentic samples were used to verify all retention times. Expected reaction products were stable to $\mathrm{GC}$ conditions.

(21) Studies using $\mathrm{FeCl}_{2}$ and $\mathrm{FeCl}_{3}$ were performed and analyzed by $\mathrm{GC}$ and $\mathrm{GC} M \mathrm{MS}$ techniques using identical conditions as reported for 1-3 (Table 1) with catalyst:OIPh:substrate $=1: 500: 2500$ ([catalyst] $=1 \mathrm{mM}$ ) All reactions were performed in $10 \% \mathrm{DMF} / \mathrm{CH}_{2} \mathrm{Cl}_{2}$ under an inert $\left(\mathrm{N}_{2}\right)$ atmosphere and followed for $12 \mathrm{~h}$.

(22) Cyclohexane and cyclohexane- $d_{12}$ studies were performed in two separate reactions with OIPh and 1; cyclooctane was used as an internal standard (1:OIPh:substrate $=1: 500: 2500,[1]=1 \mathrm{mM})$. The ratio of the product distribution of cyclohexanol:cyclooctanol and deuterated cyclohexanol:cyclooctanol yields the desired $k_{H} / k_{\mathrm{D}}$

(23) Liu, K.; Johnson, C. C.; Newcomb, M.; Lippard, S. J. J. Am. Chem. Soc. 1993, 115, 939-947.

(24) Rataj, M. J.; Kauth, J. E.; Donnelly, M. I. J. Biol. Chem. 1991 $266,18684-18690$.

(25) Green, J.; Dalton, H. Biochem. J. 1989, 259, 167-172. 6248.

Groves, J. T.; Nemo, T. E. J. Am. Chem. Soc. 1983, 105, 6243-

(27) Linsey Smith, J. R.; Mortimer, D. N. J. Chem. Soc., Chem. Commun. $1985,410-411$.

(c) 1997 American Chemical Society 
Table 1. Catalytic Properties ${ }^{a}$ of $\left[\mathrm{Fe}^{n+}, \mathrm{Fe}^{m+}\right]$ Core Oxidation States Versus Iron Prophyrin Systems

\begin{tabular}{|c|c|c|c|c|c|}
\hline substrate & products & $\begin{array}{l}{\left[\mathrm{Fe}^{2+}, \mathrm{Fe}^{2+}\right]^{b}} \\
\text { T.O. }(\text { eff } \%)^{s}\end{array}$ & $\begin{array}{l}{\left[\mathrm{Fe}^{2+}, \mathrm{Fe}^{3+}\right]^{c}} \\
\text { T.Of }(\mathrm{eff} \%)^{x}\end{array}$ & $\begin{array}{l}{\left[\mathrm{Fe}^{3+}{ }^{\left.3 e^{3+}\right]^{d}}\right.} \\
\text { T.O }(\text { eff } \%)^{g}\end{array}$ & $\begin{array}{l}\mathrm{Fe}^{3+} \text { porphyrinse } \\
\text { T.O. (yield } \%)^{h}\end{array}$ \\
\hline \multirow[t]{3}{*}{ cyclohexane } & cyclohexanol & $57(44)^{i}$ & $1(10)$ & $-(3)$ & $4(31)$ \\
\hline & cyclohexanone & 1 & 1 & - & (6) \\
\hline & chlorocyclohexane & 49 & 38 & 13 & \\
\hline \multirow[t]{3}{*}{ cyclohexene } & cyclohexene oxide & $83(58)^{i}$ & $78(64)$ & $-(10)$ & $5(55 y$ \\
\hline & cyclohexenol & 100 & 127 & 5 & (15) \\
\hline & cyclohexenone & 100 & 151 & - & (1) \\
\hline \multirow[t]{2}{*}{$\mathrm{PhSMe}$} & $\mathrm{PhS}(\mathrm{O}) \mathrm{Me}$ & $3500(93)^{k}$ & $600(45)$ & - & $84(75)^{y}$ \\
\hline & $\mathrm{PhS}(\mathrm{O})_{2} \mathrm{Me}$ & 1000 & 2 & - & (9) \\
\hline \multirow[t]{5}{*}{ toluene } & benzyl alcohol & $23(35)^{i}$ & $1(10)$ & $1(3)$ & $1.2(11)^{m}$ \\
\hline & benzaldehyde & 5 & - & 1 & 1 \\
\hline & o-cresol & 1 & 1 & - & - \\
\hline & $m$-cresol & 1 & 19 & - & - \\
\hline & $p$-cresol & 1 & 1 & - & - \\
\hline
\end{tabular}

${ }^{a}$ All reactions use OIPh as oxygen atom donor molecule. ${ }^{b} \mathrm{Fe}_{2}{ }^{2+}\left(\mathrm{H}_{2} \mathrm{Hbamb}\right)_{2}(\mathrm{~N}-\mathrm{MeIm})_{2}{ }^{c}\left[\mathrm{Fe}_{2}{ }^{2+3+}\left(\mathrm{H}_{2} \mathrm{Hbamb}\right)_{2}(\mathrm{~N}-\mathrm{Melm})_{2}\right] \mathrm{I}^{-},{ }^{d}\left[\mathrm{Fe}_{2}{ }^{3+}\left(\mathrm{H}_{2} \mathrm{Hbamb}\right)(\mathrm{N}-\right.$ $\left.\mathrm{MeIm}_{2}\right]\left(\mathrm{I}^{-}\right)_{2}{ }^{e}$ For reactions with cyclohexane and cyclohexene, [Fe(TTP)Cl], $\left(\left(5,10,15,20\right.\right.$-tetra-o-tolylporphyrinato)iron(III) chloride). ${ }^{21,34}$ For reaction with methyl phenyl sulfide, ( $\mathrm{Fe}$ (binaphthylporphyrin) $\mathrm{Cl}$ ). ${ }^{21,34}$ For reaction with toluene, [Fe(TPP)Cl] ((tetraphenylporphyrinato)iron(III) chloride). ${ }^{21}$ f Turnover numbers corrected for non-metal-catalyzed products. Total product turnover are reported for porphyrin systems. $8100 \%$ efficiency represents one substrate oxygenation per iodosylbenzene consumed. ${ }^{h}$ Yields are limited by amount of iodosylbenzene used in the reaction. ${ }^{i}$ Catalyst:OIPh:substrate $=1: 500: 2500$ ([catalyst $]=1 \mathrm{mM}$ ). All reactions were performed in $10 \% \mathrm{DMF} / \mathrm{CH}_{2} \mathrm{Cl}_{2}$ and followed for $12 \mathrm{~h}$ unless otherwise stated. ' Catalyst:OIPh:substrate 1:10:210 ([catalyst] $=0.044 \mathrm{mM}$ ). All porphyrin reactions were performed in $\mathrm{CH}_{2} \mathrm{Cl}_{2}{ }^{*} \mathrm{Catalyst}^{\circ} \mathrm{OIPh}$ : substrate $=1: 5000: 25000([$ catalyst $]=0.1 \mathrm{mM}) \cdot{ }^{l}$ Catalyst:OIPh:substrate $=1: 100: 1000\left([\right.$ catalyst $\left.]=1 \times 10^{-3} \mathrm{mM}\right) \cdot{ }^{21} \mathrm{~m}$ Catalyst:OIPh:substrate $=1: 10: 100$ ([catalyst] $\left.=1 \times 10^{-3} \mathrm{mM}\right)^{21}$

with their binuclear formulations. ${ }^{25}$ Both 2 and 3 give rise to broadened $g=4.3$ signals in their EPR spectra.

Catalytic atom transfer reactions (Table 1) were investigated under strict anaerobic conditions using OIPh as oxygen atom donor molecule and cyclohexane, cyclohexene, methyl phenyl sulfide, and toluene as substrates in $10 \% \mathrm{DMF} / \mathrm{CH}_{2} \mathrm{Cl}_{2}{ }^{28} \mathrm{All}$ complexes were stable in the absence of iodosylbenzene for over $12 \mathrm{~h}$. Parallel control reactions (absence of catalyst) were used to correct for non-metal-mediated products. Iodobenzene was recovered in quantitative yields in all reactions. The products obtained from the oxidation of cyclohexane with 1 and OIPh (cyclohexanol (57), cyclohexanone (1), and chlorocyclohexane (57)) clearly indicate the ability of 1 to catalyze the oxidation of alkanes. The effect of core oxidation states is evident from the reaction of 2 , which produces chlorocyclohexane (38) as the dominant product and only trace amounts of cyclohexanol (1). The fully oxidized complex, 3 , produces only low levels of chlorocyclohexane (13). The requirement for at least one ferrous center is more clearly evident in the catalytic oxidations of olefins such as cyclohexene. Both 1 and 2 yield primarily allylic oxidation products (cyclohexenol and cyclohexenone), although cyclohexene oxide represents a significant product ( $30 \%$ and $22 \%$, respectively). Interestingly, reactions catalyzed by 3 produce only low levels of cyclohexenol, suggesting that the $\left[\mathrm{Fe}^{3+}, \mathrm{Fe}^{3+}\right]$ core is not an effective oxygen transfer catalyst under these conditions. This conclusion is supported by results from the $2 \mathrm{e}^{-}$catalytic oxidation. of PhSMe where both 1 and 2 exhibit excellent catalytic ability while the diferric complex, 3 , is inert as a sulfide oxidation catalyst. The binuclear compound 1 oxidizes toluene to primarily produce benzylic oxidation products with only minor levels of product resulting from attack of the aromatic ring, while 2 , very interestingly, gives rise to predominantly aromatic ring oxidation products. Under identical conditions, simple $\mathrm{Fe}^{2+}$ and $\mathrm{Fe}^{3+}$ salts in the presence of OIPh were unable to catalyze any of these reactions. ${ }^{29}$ The intermolecular kinetic isotope effect for alkane $\mathrm{C}-\mathrm{H}$ oxidation was determined by the competitive oxidation of cyclohexane and cyclohexane- $d_{12}\left(k_{\mathrm{H}} / k_{\mathrm{D}}=2.2\right)^{30}$ This small intermolecular KIE is consistent with some, ${ }^{31-33}$ but not all, ${ }^{34}$ studies for the oxidation of alkanes by MMO and is indicative of only a minor contribution from $\mathrm{C}-\mathrm{H}$ bond breaking in the rate-determining step of substrate oxidation.

A comparison with the product distributions obtained from $\mathrm{OIPh}$ oxidation reactions catalyzed by iron porphyrins, whose mechanisms invoke a reactive high-valent $\left[\mathrm{Fe}^{4+}=\mathrm{O}\right]$ species, ${ }^{21-23}$ is presented in Table 1. While Fe(TPP)Cl-catalyzed oxidations of cyclohexane do not form any chlorinated product in the presence of $\mathrm{CH}_{2} \mathrm{Cl}_{2}$, brominated products are reported in the reaction of cycloheptane in $\mathrm{CH}_{2} \mathrm{Br}_{2} \cdot{ }^{35}$ Furthermore, the ability of 1 and 2 to catalyze the oxidations of alkanes is substantially quenched when polar solvents such as $\mathrm{CH}_{3} \mathrm{CN}$ are used instead of hydrophobic solvents such as $\mathrm{CH}_{2} \mathrm{Cl}_{2}$. An analogous phenomenon, ascribed to competition between solvent and the oxygen atom donor molecules for the labile site on the iron center, is also known for the porphyrin systems. ${ }^{36}$ In the absence of substrate, 1 reacts with OIPh to yield a $\mu$-oxo $\mathrm{Fe}^{3+}$ dimer, which is inert as an oxygen-atom transfer catalyst. Differences in the catalytic chemistry observed for 1 and $\mathbf{2}$ and that reported for $\left[\mathrm{Fe}_{2}{ }^{2+}\left(\mathrm{H}_{2} \mathrm{Hbab}\right)_{2}(\mathrm{~N} \text {-MeIm })_{2}\right]$ are thought to reflect the greater ease by which the core redox properties induced by the $\mathrm{H}_{2}$ bamb ${ }^{2-}$ ligand support formation of the reactive intermediate. ${ }^{18,19}$

These data demonstrate for the first time the ability of simple binuclear non-heme iron complexes containing at least one ferrous center to act as efficient oxygen-atom transfer catalysts using $\mathrm{OIPh}$ as the donor molecule. The chemistry exhibited by 1 and 2 clearly mimics many of the reactions heretofore seen only for heme systems, indicating that simple N/O ligand environments are adequate to support oxidative chemistry by oxygen atom donor molecules. Although the reactive intermediate(s) responsible for the observed alkane, arene, alkene, and sulfide oxidation chemistry exhibited by 1 and 2 is not as yet defined, its reactivity pattern is analogous to that observed for Cyt P-450, synthetic high-valent iron-oxo radical cation porphyrin model species, ${ }^{22,23}$ and the putative binuclear highvalent iron species observed in the catalytic cycle of MMO. 4.5 Current efforts are designed to examine the effect of alternative oxygen-atom donors and metal-based redox potential on catalysis, elucidate the intimate mechanism of oxygen-atom transfer via isotopic labeling studies, and identify and spectroscopically characterize the reactive intermediate(s) responsible for this chemistry.

Supporting Information A vailable: Electrochemical UV/vis, and EPR spectroscopic characterization of 1-3 (5 pages). See any current masthead page for ordering and Internet access instructions.

JA9709482 


\title{
Skirting the oxo-wall: characterization and catalytic reactivity of

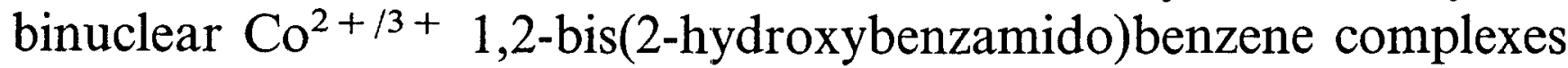 with comparison to their isostructural $\mathrm{Fe}^{2+13+}$ analogs. Implications of d-electron count on oxygen atom transfer catalysis
}

\author{
Subhasish Mukerjee ${ }^{\text {a }}$, Kirsten Skogerson ${ }^{\text {a }}$, Susan DeGala ${ }^{\text {a }}$, John P. Caradonna ${ }^{\text {b,* }}$ \\ a Department of Chemistry, Kline Laboratory, Yale University, PO Box 208107, New Haven, CT 06520-8107, USA \\ ${ }^{b}$ Department of Chemistry, Boston University, 590 Commonwealth Ave., Boston, MA 02215.2521, USA
}

Received 27 April 1999; accepted 28 September 1999

\begin{abstract}
The reaction of $\mathrm{Co}^{2+}(N-\mathrm{MeIm})_{2}(\mathrm{Cl})_{2}$ (1), with $\mathrm{Li}_{2} \mathrm{H}_{2} \mathrm{Hbab}\left(\mathrm{H}_{4} \mathrm{Hbab}=1\right.$,2-bis(2-hydroxybenzamido)benzene) affords the binuclear complex $\left[\mathrm{Co}_{2}{ }^{2}+\left(\mathrm{H}_{2} \mathrm{Hbab}\right)_{2}(\mathrm{~N} \text {-MeIm) })_{2}\right]$ (2). Single crystal X-ray crystallography shows that the two $\mathrm{Co}^{2+}$ centers in 2 are related by a crystallographically imposed center of symmetry with the coordination sphere around each metal center composed of amide oxygens, terminal and bridging phenolate oxygen atoms and a single nitrogen from $N$-methylimidazole. 2 is isostructural to the $\mathrm{Fe}^{2+}$ complex, $\left[\mathrm{Fe}_{2}\left(\mathrm{H}_{2} \mathrm{Hbab}\right)_{2}(N-\mathrm{MeIm})_{2}\right](5)$, previously reported from our laboratory (A. Stassinopoulos, G. Schulte, G.C. Papaefthymiou, J.P. Caradonna, J. Am. Chem. Soc. 113 (1991) 8686-8697). Stoichiometric iodometric oxidation of 2 yields the mixed valence complex $\left[\mathrm{Co}^{2+} \mathrm{Co}^{3}+\left(\mathrm{H}_{2} \mathrm{Hbab}\right)_{2}(N \text {-MeIm})_{2}\right]^{+}(3)$, and the oxidized complex $\left[\mathrm{Co}_{2}{ }^{3}+\left(\mathrm{H}_{2} \mathrm{Hbab}\right)_{2}(N \text {-MeIm})_{2}\right]^{2+}(4)$. The UV-Vis spectrum of 2 shows ligand field transitions at $600 \mathrm{~nm}\left(\varepsilon_{\mathrm{M}}=160\right)$ and $540 \mathrm{~nm}\left(\varepsilon_{\mathrm{M}}=120\right)$ and a phenolate-to-Co $\mathrm{Co}^{2+}$ ligand-to-metal charge-transfer (LMCT) band at $327 \mathrm{~nm}\left(\varepsilon_{\mathrm{M}}=23600\right)$. Oxidation of the dicobalt core results in a bathchromic shift of the LMCT band (3: $\left.305 \mathrm{~nm}\left(\varepsilon_{M}=17400\right), 334 \mathrm{~nm}\left(\mathrm{sh}, \varepsilon_{\mathrm{M}}=14500\right) ; 4: 295 \mathrm{~nm}\left(\varepsilon_{\mathrm{M}}=21000\right), 357 \mathrm{~nm}\left(\varepsilon_{\mathrm{M}}=15000\right)\right)$. EPR spectra of 2 and 3 at $4 \mathrm{~K}$ show broad resonances from 500 to 4500 Gauss indicative of the presence of strong zero-field splitting effects, while 4 is EPR silent. Solution magnetic susceptibility measurements for $2\left(S_{1}=S_{2}=3 / 2 ; \mu_{\mathrm{B}}=6.90\right)$ are consistent with a weakly interacting high-spin $\mathrm{Co}^{2+}$ dimer. Analogous measurements for $3\left(S_{1}=3 / 2, S_{2}=0 ; \mu_{\mathrm{B}}=4.78\right)$ and $4\left(S_{1}=S_{2}=0 ; \mu_{\mathrm{B}}=0.25\right)$ indicate the presence of a single high-spin $\mathrm{Co}^{2}+$ for 3 and a diamagnetic core for 4 , consistent with the latter's ${ }^{1} \mathrm{H}$ NMR spectrum. Complexes 2-4 exhibit the ability to catalytically oxidize a variety of organic substrates (olefins, sulfides) using iodosylbenzene (OIPh) as oxygen atom donor. Reactions with olefin substrates (norbornene, cyclooctene, styrene) yield solely epoxide products while cyclohexene afforded $85 \%$ epoxide with small amounts (15\%) of allylic oxidation products. Oxygen atom transfer to olefins occurs with high but not exclusive retention of stereochemistry. The mechanistic implications of the significantly different product distributions obtained with the $\mathrm{Co}^{2+}\left(\mathrm{d}^{7}\right)$ dimer, 2, versus the isostructural $\mathrm{Fe}^{2+}\left(\mathrm{d}^{6}\right)$ dimer, 5 (A. Stassinopoulos, J.P. Caradonna, J. Am. Chem. Soc. 112 (1990) 7071-7073), are presented. These data strongly infer the operation of two independent mechanisms for the $\mathrm{Co}^{2+}$ and $\mathrm{Fe}^{2+}$ catalyzed reactions. 02000 Elsevier Science S.A. All rights reserved.
\end{abstract}

Keywords: Oxygen atom transfer; Iron binuclear complexes; Cobalt binuclear complexes; Catalytic reactivity; d-Electron count

Abbreviations: $\mathrm{H}_{4} \mathrm{Hbab}, 1$,2-bis(2-hydroxybenzamido)benzene; $\mathrm{N}$ MeIm, $N$-methyl imidazole; salen, $N, N^{\prime}$-ethylenebis(salicylideneimine); TBAT, tetrabutylammonium tetrafluoro-borate; OIPh, iodosylbenzene; MCPBA, meta-chloroperbenzoic acid; Pedab, $N, N, N^{\prime}, N^{\prime}-$ tetrakis-(2-pyridylethyl(1,3-diaminomethylbenzene); OTf, $-\mathrm{SO}_{3} \mathrm{CF}_{3}$; $\mathrm{H}_{2} \mathrm{Bpb}, 1$,2-bis(2-pyridine-carboxamido)benzene); $\mathrm{Cl}_{4} \mathrm{Me}_{4} \mathrm{Salam}, 2,2^{\prime}$, 4,4'-tetrachloro-8,8,8, $8^{\prime}$-tetramethylsalam $\mathrm{H}_{2}$.

* Corresponding author. Tel.: + 1-617-353 1692; fax: + 1-617-353 6466.

\section{Introduction}

Recent advances in the field of monooxygenase reactivity models have begun to shed light on the intimate mechanisms of catalytic oxygenation reactions [1]. Initial efforts focused on elucidating the principles governing heme dependent oxidation reactions. These studies include examining the primary redox event with dioxy- 
gen (or abiological oxygen atom donor molecules) that leads to formation of the reactive intermediate, characterization of the reactive intermediate(s), and investigating the mechanism of oxygen atom transfer to a variety of organic substrates. Current efforts are directed at improving the regioselective and enantioselective oxidation properties of these heme based catalysts by altering the nature of the transition metal center and the substituents of the heme group and/or axial ligand [1].

The pronounced effect of 'd-electron count' on the ability of heme-based complexes to catalyze the oxidation of organic substrates is well documented [1c,2]. Studies have shown that while $\mathrm{Ti}^{2+}\left(\mathrm{d}^{2}\right)$ and $\mathrm{V}^{2+}\left(\mathrm{d}^{3}\right)$ porphyrin complexes are unable to efficiently catalyze the oxygen atom transfer reaction between OIPh and simple substrates such as olefins, $\mathrm{Cr}^{3+}\left(\mathrm{d}^{3}\right)$ porphyrins are competent stereospecific epoxidation catalysts although large amounts of allylic oxidation are observed for cyclic olefins. While $\mathrm{Mn}^{3+}\left(\mathrm{d}^{4}\right)$ porphyrin complexes are efficient olefin epoxidation catalysts, this chemistry is characterized by a large loss of stereoselectivity. These results are in contrast to the OIPh epoxidation of olefins catalyzed by $\mathrm{Fe}^{3+}\left(\mathrm{d}^{5}\right)$ porphyrins, which is stereospecific and in many instances demonstrates a strong reactivity preference for cis-olefins compared to the trans-isomer. $\mathrm{Co}^{3}+\left(\mathrm{d}^{6}\right)$ porphyrins are poor catalysts for the OIPh epoxidation of olefins, while the corresponding $\mathrm{Ni}^{2+}\left(\mathrm{d}^{8}\right)$ and $\mathrm{Cu}^{2+}\left(\mathrm{d}^{9}\right)$ complexes are effectively inert.

This trend can be understood by recognizing that high valent metal-oxo porphyrin species are responsible for most of the products arising from metalloporphyrin catalyzed oxidations of organic substrates [1,2]. The detailed spectroscopic and reactivity characteristics of a series of porphyrin $\left[\mathrm{M}^{4+}=\mathrm{O}\right](\mathrm{M}=\mathrm{Cr}, \mathrm{Mn}$, and $\mathrm{Fe})$ complexes have been reviewed recently $[1 \mathrm{~b}, \mathrm{c}]$. Poor oxygen atom transfer is expected from early transition metal centers that are highly oxophilic and can form stable $M=O$ moieties under ambient conditions. Since oxidation of substrates requires the transfer of the oxygen atom coordinated to the metal center, the kinetic inertness of titanium and vanadium porphyrins and the low activity of the chromium complexes can be explained. The high activity of $\mathrm{Mn}^{3+}$ and $\mathrm{Fe}^{3+}$ porphyrin complexes and the relatively low activity of $\mathrm{Ru}^{3+}$ and $\mathrm{Os}^{3+}$ porphyrin systems can be similarly rationalized.

While such metal-oxo systems are typically depicted as $\mathrm{M}=\mathrm{O}$, its true bond order depends on the $\mathrm{d}^{n}$ configuration, the coordination stereochemistry and the existence and nature of a trans ligand $[3,4]$. Furthermore, $\mathrm{M}=\mathrm{O}$ groups are stabilized only at those centers that

$$
M^{n}-0 \rightleftharpoons M^{n-1}=0 \rightleftharpoons M^{n-2} \equiv 0^{+}
$$

Scheme 1 . have an oxidation state of at least $4+$ and a $d^{0}-d^{4}$ electron configuration. The canonical forms of the $\mathrm{M}=\mathrm{O}$ bond indicate that in order to induce a charge distribution, the metal center must be electron deficient and an acceptor (Scheme 1). Only metal centers with $d^{0}-d^{4}$ electron configurations have the required vacant or half-filled acceptor orbitals. To date, no stable $\mathrm{M}=\mathrm{O}$ moieties are documented for any transition metal to the right of Group 8. This suggests, therefore, the presence of an 'oxo-wall' separating the transition metal ions into two distinct classes with regards to the formation of $\mathrm{M}=\mathrm{O}$ moieties.

The reported reactivity properties of $\mathrm{Co}^{3+}, \mathrm{Ni}^{2+}$ and $\mathrm{Cu}^{2+}$ porphyrin complexes are consistent with the presence of the 'oxo-wall'; both $\mathrm{Ni}^{2+}$ and $\mathrm{Cu}^{2}+$ complexes are inert as epoxidation catalysts while $\mathrm{Co}^{3+}$ porphyrins are poor epoxidation catalysts but potent autooxidation initiators $[1 b, c, 2]$. Recent studies examining the ability of redox inactive as well as redox active metal centers to catalyze the OIPh epoxidation of olefins suggest that metal complexes can catalyze the epoxidation of olefins by pathways that do not involve high valent metal-oxo intermediates $[5,6]$. The similarity of the product distributions for redox inactive $\left(\mathrm{Zn}^{2+}\right.$, $\left.\mathrm{Al}^{3+}\right)$ and redox active $\left(\mathrm{Fe}^{3+}, \mathrm{Mn}^{2+}, \mathrm{Cu}^{2+}, \mathrm{Co}^{2+}\right)$ metals suggest a common intermediate $[5,6]$. Such pathways, proposed to involve the direct reaction of the olefinic substrate with a metal complex of a hypervalent iodine ligand rather than high valent metal-oxo intermediates [5,6], are consistent with the low levels of products observed in the cobalt porphyrin catalyzed OIPh epoxidation of olefins.

The investigation of mononuclear and binuclear nonheme iron monooxygenases is a topic of interest to the inorganic community owing to the ability of these centers to act as alkane/arene oxidation catalysts [7]. Our efforts in this area are directed towards understanding the intimate role played by the iron center during the catalytic oxidation of organic substrates $[7 a, 8,9]$. We have previously described the structural, spectroscopic and reactivity properties of a binuclear ferrous analog reaction system, $\left[\mathrm{Fe}_{2}{ }^{2+}\left(\mathrm{H}_{2} \mathrm{Hbab}\right)_{2}(\mathrm{~N}-\right.$ $\left.\mathrm{MeIm})_{2}\right](5)$, that is a reasonable approximation to the electronic environment of the reduced binuclear active site of methane monooxygenase as judged by Mössbauer, EPR and magnetic susceptibility data comparisons $[8,9]$. Of equivalent interest is the ability of 5 to heterolytically cleave the percarboxylic $\mathrm{O}-\mathrm{O}$ bond of phenylperacetic acid and catalyze the $\mathrm{OIPh}$ oxidation of a variety of simple organic substrates yielding both 'oxenoid'-like and radical-like products in a manner analogous to that reported for cytochrome P.450 and MMO [8]. These data were consistent with two limiting mechanisms involving either coordination of hypervalent iodine(III) of OIPh to the $\mathrm{Fe}^{2+}$ center leading to 
oxygen activation (Lewis acid catalyzed oxygen atom transfer) or the formal formation of a high valent Fe-oxenoid species [8].

Despite the mechanistic insights gained from examining the influence of d-electron count on the reactivity properties of heme complexes, the comparison of isostructural binuclear metal complexes capable of catalyzing oxygen atom transfer reactions remains relatively unexplored [7]. Herein, we extend our studies from the binuclear $\mathrm{d}^{6} \mathrm{Fe}^{2+}$ system, 5 , to an isostructural $\mathrm{d}^{7}$ $\mathrm{Co}^{2+}$ system, $\left[\mathrm{Co}_{2}{ }^{2+}\left(\mathrm{H}_{2} \mathrm{Hbab}\right)_{2}(N-\mathrm{MeIm})_{2}\right](2)$, and its oxidized mixed-valence complex $\left[\mathrm{Co}^{2}+\mathrm{Co}^{3+}\right.$ $\left.\left(\mathrm{H}_{2} \mathrm{Hbab}\right)_{2}(\mathrm{~N} \text {-MeIm })_{2}\right]^{+}(3)$, and fully oxidized complex $\left[\mathrm{Co}_{2}{ }^{3+}\left(\mathrm{H}_{2} \mathrm{Hbab}\right)_{2}(N-\mathrm{MeIm})_{2}\right]^{2+}(4)$, with the objective of examining the effect of crossing the 'oxo-wall' on metal centered catalytic oxygen atom transfer reactions. In this study we report the ability of complexes $\dot{2}_{-4}$ to catalyze the epoxidation of a variety of olefins with little tendency to yield allylic oxidation products that are observed as the primary reaction products of reactions catalyzed by $\left[\mathrm{Fe}_{2}{ }^{2+}\left(\mathrm{H}_{2} \mathrm{Hbab}\right)_{2}(N-\mathrm{MeIm})_{2}\right](5)[8]$. A comparison of the reactivity properties of the binuclear complexes $\left[\mathrm{Fe}^{2+} \mathrm{Fe}^{2+}\right](5) ;\left[\mathrm{Fe}^{2+} \mathrm{Fe}^{3+}\right](6) ;\left[\mathrm{Fe}^{3+}\right.$ $\left.\mathrm{Fe}^{3+}\right](7)$, and $\left[\mathrm{Co}^{2+}, \mathrm{Co}^{2+}\right]$ systems is presented along with their mechanistic implications.

\section{Experimental}

\subsection{Methods and materials}

The diamide ligand $\mathrm{H}_{4} \mathrm{Hbab}$ and its dilithium salt $[8,10]$, and iodosylbenzene [11] were prepared by published methods. Anhydrous $\mathrm{CoCl}_{2}$ (pale blue) was prepared by heating violet $\mathrm{CoCl}_{2} \cdot 6 \mathrm{H}_{2} \mathrm{O}$ under vacuum for $48 \mathrm{~h}$. All other reagents were purchased from standard commercial sources and purified by standard methods. Solvents were appropriately purified, dried, and degassed prior to use. $\mathrm{Co}^{2+}($ salen $)[12],\left[\mathrm{Co}^{3+}(\right.$ salen $\left.)\right] \mathrm{Cl}$ [13] and $\mathrm{Fe}_{2}\left(\mathrm{H}_{2} \mathrm{Hbab}\right)_{2}(\mathrm{~N}-\mathrm{MeIm})_{2}(5)[8,9]$, were synthesized by literature procedures.

\section{2. $\mathrm{Co}^{2+}(\mathrm{N}-\mathrm{MeIm})_{2}(\mathrm{Cl})_{2}(1)$}

The synthesis of monomeric 1 was adapted from literature procedures for the synthesis of $\mathrm{Co}^{2+} \mathrm{A}_{2} \mathrm{X}_{2}$ compounds [14]. All operations were carried out under an $\mathrm{N}_{2}$ atmosphere using standard anaerobic techniques. Anhydrous $\mathrm{CoCl}_{2}(4.00 \mathrm{~g}, 30.8 \mathrm{mmol})$ was dissolved in a minimal amount of $\mathrm{MeOH}(30 \mathrm{ml})$ yielding a vivid blue solution which was then filtered into a stirred solution of $4.9 \mathrm{ml}(62 \mathrm{mmol})$ of $N$-MeIm in $7 \mathrm{ml}$ of $\mathrm{MeOH}$. This addition immediately gave a blue precipitate. The reaction was allowed to proceed overnight after which the precipitate was collected by Schlenk filtration techniques and dried overnight under vacuum to yield $7.64 \mathrm{~g}(70 \%$ yield $)$ of blue $\mathrm{Co}^{2+}(\mathrm{N}$ MeIm $)_{2}(\mathrm{Cl})_{2}$. Anial. Calc. for $\mathrm{C}_{8} \mathrm{H}_{12} \mathrm{~N}_{4} \mathrm{CoCl}_{2}: \mathrm{C}, 32.97$; H, 4.11; N, 19.00; Co, 20.83. Found: C, 32.65; H, 4.08; $\mathrm{N}, 19.04$; Co, 20.03\%. Absorption spectrum (DMF): $\lambda_{\max }\left(\varepsilon_{\mathrm{M}}\right) 630 \mathrm{~nm}(602), 611 \mathrm{~nm}(569) ; 579 \mathrm{~nm}(349)$, $220(17800)$. Infrared spectrum $(\mathrm{KBr}) v_{\text {vinylic }} \mathrm{C}-\mathrm{H}=3145$ $\mathrm{cm}^{-1}, \quad v_{\mathrm{N}-\text { methy! }}=3122 \mathrm{~cm}^{-1}, \quad v_{\text {ring }}, \operatorname{stretch}\left(R_{1}\right)=1539$, $1521 \mathrm{~cm}^{-1}, v_{\text {ring }} \operatorname{stretch}\left(R_{2}\right)=1507 \mathrm{~cm}^{-1}, v_{\text {ring }} \operatorname{stretch}\left(R_{4}\right)=$ $1335 \mathrm{~cm}^{-1}, v_{\text {ring } \operatorname{strech}\left(R_{5}\right)}=1232 \mathrm{~cm}^{-1}$. This complex is stable in air as a solid and as a methanolic solution.

\section{3. $\mathrm{Co}_{2}\left(\mathrm{H}_{2} \mathrm{Hbab}\right)_{2}(\mathrm{~N}-\mathrm{MeIm})_{2} \mathrm{MeOH}(2)$}

All operations were carried out under $\mathrm{N}_{2}$ atmosphere. To a stirred solution of $0.5 \mathrm{~g}$ of $\mathrm{Co}(\mathrm{N}$ $\mathrm{MeIm})_{2}(\mathrm{Cl})_{2}(1),(1.7 \mathrm{mmol})$ in $10 \mathrm{ml}$ of methanol was added a filtered solution of $0.62 \mathrm{~g}(1.7 \mathrm{mmol})$ of $\mathrm{Li}_{2} \mathrm{H}_{2} \mathrm{Hbab}$ in $15 \mathrm{ml}$ of methanol. The blue solution of the Co-monomer turned darker on addition of the ligand; after stirring overnight a lavender-colored precipitate formed which was filtered from solution and dried to give $1.0 \mathrm{~g}(60 \%)$ of the pure product soluble in DMF and DMSO and insoluble in other common organic solvents. Anal. Calc. for $\mathrm{C}_{49} \mathrm{H}_{44} \mathrm{Co}_{2} \mathrm{~N}_{8} \mathrm{O}_{9}: \mathrm{C}$, 58.44; H, 4.37; N, 11.13; Co, 11.72. Found: C, 58.20; H, 4.12 ; N, 11.43; Co, $12.08 \%$. Absorption spectrum (DMF): $\lambda_{\max }\left(\varepsilon_{\mathrm{M}}\right) 600 \mathrm{~nm}(160), 540 \mathrm{~nm}(120), 327 \mathrm{~nm}$ (sh, 23600). Infrared spectrum $(\mathrm{KBr}) v_{\text {amideNH }}=3450$ $\mathrm{cm}^{-1}, v_{\text {amideco }}=1640 \mathrm{~cm}^{-1}$. This complex is stable in air for several hours as a solid but gets rapidly oxidized in solution.

\section{4. $\left[\left(\mathrm{Co}^{2+} \mathrm{Co}^{3+}\left(\mathrm{H}_{2} \mathrm{Hbab}\right)_{2}(\mathrm{~N}-\mathrm{MeIm})_{2}\right)\right]\left(\mathrm{I}^{-}\right)(2 \mathrm{DMF})$}

(3)

Under a $\mathrm{N}_{2}$ atmosphere, $0.025 \mathrm{~g}(0.1 \mathrm{mmol}) \mathrm{I}_{2}$ in distilled and degassed DMF was slowly added to a DMF solution of $0.2 \mathrm{~g}(0.2 \mathrm{mmol}) 2$. The solution was stirred overnight and the solvent evaporated under reduced pressure. The resulting solid was washed with dry degassed pentane to give a dull green solid. Anal. Calc. for $\mathrm{C}_{54} \mathrm{H}_{54} \mathrm{Co}_{2} \mathrm{~N}_{10} \mathrm{O}_{10} \mathrm{I}: \mathrm{C}, 46.51 ; \mathrm{H}, 3.87 ; \mathrm{N}$, 10.05; Co, 8.47. Found: C, 46.67; H, 3.99; N, 10.30; Co, $8.70 \%$. Absorption spectrum (DMF) $\lambda_{\max }\left(\varepsilon_{\mathrm{M}}\right): 305 \mathrm{~nm}$ (17400), $334 \mathrm{~nm}$ (sh, 14500). Infrared spectrum: $v_{\text {amideNH }}=3400 \mathrm{~cm}^{-1}, v_{\text {amideCo }}=1656 \mathrm{~cm}^{-1}$.

\section{5. $\left[\left(\mathrm{Co}_{2}{ }^{3+}\left(\mathrm{H}_{2} \mathrm{Hbab}\right)_{2}(\mathrm{~N}-\mathrm{MeIm})_{2}\right)\left(2 \mathrm{I}^{-}\right)\right](3 \mathrm{DMF})$ (4)}

Under a $\mathrm{N}_{2}$ atmosphere, $0.076 \mathrm{~g}(0.3 \mathrm{mmol}$, excess $)$ of $I_{2}$ was added to $0.2 \mathrm{~g}(0.2 \mathrm{mmol})$ of 2 in $1 \%$ $\mathrm{DMF} / \mathrm{CH}_{2} \mathrm{Cl}_{2}$ solution. After refluxing overnight, a greenish brown solid was precipitated out of the solution by the addition of diethyl ether. The solid was filtered and dried under vacuum. Anal. Calc. for $\mathrm{C}_{57} \mathrm{H}_{61} \mathrm{Co}_{2} \mathrm{~N}_{11} \mathrm{O}_{11} 2 \mathrm{I}: \mathrm{C}, 47.74 ; \mathrm{H}, 4.11 ; \mathrm{N}, 10.85 ; \mathrm{Co}$, 
Table 1

Crystallographic parameters for $\mathrm{Co}^{2}+(N-\mathrm{MeIm})_{2}(\mathrm{Cl})_{2}$ (1) and $\mathrm{Co}_{2}{ }^{2+}\left(\mathrm{H}_{2} \mathrm{Hbab}\right)_{2}(N-\mathrm{MeIm})_{2}(2)$

\begin{tabular}{|c|c|c|}
\hline & 1 & 2 \\
\hline Formula & $\mathrm{C}_{8} \mathrm{H}_{12} \mathrm{~N}_{4} \mathrm{Cl}_{2} \mathrm{Co}$ & $\mathrm{C}_{24} \mathrm{H}_{20} \mathrm{O}_{4} \mathrm{~N}_{4} \mathrm{Co}$ \\
\hline Formula weight, amu & 294.05 & 487.38 \\
\hline Crystal colour & blue & lavender \\
\hline Crystal habit & parallelogram & parallelepipeds \\
\hline Temperature $(\mathrm{K})$ & 296 & 296 \\
\hline Crystal system & monoclinic & triclinic \\
\hline Space group & $P 2_{1} / n$ (no. 14$)$ & $P 1$ (no. 2) \\
\hline$a(\dot{A})$ & $7.9840(9)$ & $10.012(2)$ \\
\hline$b(\dot{A})$ & $12.554(2)$ & $12.830(2)$ \\
\hline$c(\dot{A})$ & $12.962(1)$ & $9.948(2)$ \\
\hline$\alpha\left({ }^{\circ}\right)$ & & $93.67(2)$ \\
\hline$\beta\left(\left(^{\circ}\right)\right.$ & $101.227(8)$ & $119.02(1)$ \\
\hline$\gamma\left({ }^{\circ}\right)$ & & $96.42(2)$ \\
\hline$V\left(\dot{A}^{3}\right)$ & $1274.4(5)$ & $1100.0(4)$ \\
\hline$z$ & 4 & 2 \\
\hline$\rho_{\text {calc }}\left(\mathrm{g} \mathrm{cm}^{-3}\right)$ & 1.533 & 1.471 \\
\hline Crystal dimension (mm) & $0.20 \times 0.36 \times 0.52$ & $0.70 \times 0.50 \times 0.25$ \\
\hline Radiation & $\begin{array}{l}\text { Mo K } \alpha \\
(\lambda=0.71069)\end{array}$ & $\begin{array}{l}\mathrm{Cu} \mathrm{K} \alpha \\
(\lambda=1.54178 \dot{A})\end{array}$ \\
\hline$\mu\left(\mathrm{cm}^{-1}\right)$ & 17.42 & 67.28 \\
\hline Scan type & $\omega$ & $\omega$ \\
\hline $2 \theta$ Range $\left({ }^{\circ}\right)$ & 49.9 & 120.0 \\
\hline No. reflections measured & 2360 & 3281 \\
\hline No. independent reflection & $1758 I 3 \sigma(I)$ & $1631 I 3 \sigma(I)$ \\
\hline No. least-square parameters & 136 & 298 \\
\hline Reflection/parameters & 12.93 & 5.47 \\
\hline$R\left(F_{\mathrm{o}}\right)(\%)$ & 3.8 & 5.1 \\
\hline$R_{\mathrm{w}}\left(F_{\mathrm{o}}\right)(\%)$ & 4.6 & 4.9 \\
\hline Goodness-of-fit & 2.04 & 1.35 \\
\hline$\rho$-factor & 0.03 & 0.06 \\
\hline
\end{tabular}

8.61. Found: C, 47.58; H, 4.23; N, 10.63; Co, 8.44\%. Absorption spectrum (DMF): $\lambda_{\max }\left(\varepsilon_{\mathrm{m}}\right): 295 \mathrm{~nm}$ $(21000), 357 \mathrm{~nm}(15000)$. Infrared spectrum $(\mathrm{KBr})$ : $v_{\text {amideNH }}=3400 \mathrm{~cm}^{-1} v_{\text {amideco }}=1660 \mathrm{~cm}^{-1}$.

2.6. Collection and reduction of $X$-ray data. $\mathrm{Co}^{2+}(\mathrm{N}-\mathrm{MeIm})_{2}(\mathrm{Cl})_{2}(\mathrm{1})$

A blue parallelogram crystal of 1 having approximate dimensions of $0.20 \times 0.36 \times 0.52 \mathrm{~mm}$ was mounted in a glass capillary. All measurements were made on an Enraf-Nonius CAD4 diffractometer with graphitemonochromated Mo $\mathrm{K} \alpha$ radiation $(\lambda=0.71073 \AA)$. Cell constants and an orientation matrix for data collection obtained from a least-squares refinement using the setting angles of 20 carefully centered reflections in the range $18.30<2 \theta<21.90^{\circ}$ corresponding to a monoclinic cell with dimensions: $a=7.9840(9), b=12.554(2)$, $c=12.962(1) \AA, \beta=101.227(8)^{\circ}$ and $V=1274.4(5) \AA^{3}$. For $Z=4$ and $F W=294.05$ the calculated density is
$1.533 \mathrm{~g} \mathrm{~cm}^{-3}$. Based on the systematic absences of $h 01$ : $h+1=2 n+1 ; 0 k 0: k=2 n+1$, and the successful solution and refinement of the structure, the space group was determined to be: $P 2_{1} / n$ (no.14). The data were collected at a temperature of $23 \pm 1^{\circ} \mathrm{C}$ using the $\omega-2 \theta$ scan technique to a maximum $2 \theta$ value of $49.9^{\circ}$. Omega scans of several intense reflections made prior to data collection had an average width at half height of $0.29^{\circ}$ with a take-off angle of $2.8^{\circ}$. Scans of $(0.80+$ $0.35 \tan \theta)^{\circ}$ were made at variable speeds ranging from 1.0 to $5.5^{\circ} \mathrm{min}^{-1}$ (in omega). Moving-crystal moving counter background measurements were made by scanning in additional $25 \%$ above and below the scan range. The counter aperture consisted of a variable horizontal slit with a width ranging from 2.0 to $2.5 \mathrm{~mm}$ and a vertical slit set to $2.0 \mathrm{~mm}$. The diameter of the incident beam collimator was $1.3 \mathrm{~mm}$ and the crystal to detector distance was $21 \mathrm{~cm}$. For intense reflections an attenuator was automatically inserted in front of the detector.

Of the 2536 reflections that were collected, 2360 were unique $\left(R_{\text {int }}=0.80\right)$. The intensities of two representative reflections that were measured after every $60 \mathrm{~min}$ of $\mathrm{X}$-ray exposure time remained constant throughout data collection indicating crystal and electronic stability (no decay correction was applied). The linear absorption coefficient for Mo $\mathrm{K} \alpha$ is $17.4 \mathrm{~cm}^{-1}$. An empirical absorption correction based on azimuthal scans of several reflections was applied which resulted in transmission factors ranging from 0.84 to 1.00 . The data were corrected for Lorentz and polarization effects.

The structure was solved by Patterson methods [15]. The non-hydrogen atoms were refined anisotropically. The final cycle of full-matrix least-squares refinement was based on 1758 observed reflections $(I>3.00 \sigma(I))$ and 136 variable parameters and converged (largest parameter shift was 0.02 times its e.s.d.) with unweighted and weighted agreement factors of $R=0.038$ and $R_{\mathrm{w}}=0.046$. The standard deviation of an observation of unit weight was 2.04 . The weighting scheme was based on counting statistics and included a factor $(p=$ 0.03 ) to downweight the intense reflections: Plots of $\Sigma w\left(\left|F_{\mathrm{o}}\right|-\left|F_{\mathrm{c}}\right|\right)^{2}$ versus $\left|F_{\mathrm{o}}\right|$ reflection order in data collection $\sin \theta / \lambda$ and various classes of indices showed no unusual trends. The maximum and minimum peaks on the final difference Fourier map corresponded to 0.47 and $-0.67 \mathrm{e} \AA^{-3}$, respectively. Neutral atom scattering factors were taken from Cromer and Waber [16]. Anomalous dispersion effects were included in $F_{\text {calc }}[17]$; the values for $\Delta f^{\prime}$ and $\Delta f^{\prime \prime}$ were those of Cromer [18]. All calculations were performed using the TEXSAN [19] crystallographic software package of Molecular Structure Corporation. Some details of the crystallographic data are given in Table 1, positional parameters for important atoms are given in Table 2, and selected bond distances and angles are provided in Table 3 . 
Table 2

Positional parameters and equivalent isotropic temperature factors for the non-hydrogen atoms of $\mathrm{Co}^{2+}(N-\mathrm{MeIm})_{2}(\mathrm{Cl})_{2}(1)^{\text {a }}$

\begin{tabular}{|c|c|c|c|c|}
\hline Atom & $x$ & $y$ & $z$ & $B_{\mathrm{eq}}\left(\dot{\mathrm{A}}^{2}\right)$ \\
\hline Co & $0.14238(6)$ & $0.21646(4)$ & $0.29249(3)$ & $3.18(2)$ \\
\hline $\mathrm{Cll}$ & $0.2471(1)$ & $0.36718(8)$ & $0.37466(8)$ & $4.70(4)$ \\
\hline $\mathrm{Cl} 2$ & $-0.1399(1)$ & $0.20792(9)$ & $0.22826(8)$ & $4.63(4)$ \\
\hline N1 & $0.2459(3)$ & $0.1885(2)$ & $0.1661(2)$ & $3.3(1)$ \\
\hline N2 & $0.2752(4)$ & $0.1300(2)$ & $0.0113(2)$ & $3.8(1)$ \\
\hline N3 & $0.2038(4)$ & $0.1000(2)$ & $0.3993(2)$ & $3.8(1)$ \\
\hline N4 & $0.2959(4)$ & $0.0186(2)$ & $0.5484(2)$ & $4.0(1)$ \\
\hline $\mathrm{Cl}$ & $0.4146(4)$ & $0.1990(3)$ & $0.1569(3)$ & $4.0(2)$ \\
\hline $\mathrm{C} 2$ & $0.4320(5)$ & $0.1625(3)$ & $0.0625(3)$ & $4.4(2)$ \\
\hline C3 & $0.2327(6)$ & $0.0794(4)$ & $-0.0919(3)$ & $5.7(2)$ \\
\hline $\mathrm{C} 4$ & $0.1670(4)$ & $0.1458(3)$ & $0.0766(3)$ & $3.5(1)$ \\
\hline C5 & $0.1716(7)$ & $-0.0064(4)$ & $0.3869(3)$ & $6.1(2)$ \\
\hline C6 & $0.2281(7)$ & $-0.0568(3)$ & $0.4784(4)$ & $6.3(2)$ \\
\hline C7 & $0.3762(7)$ & $0.0009(4)$ & $0.6587(3)$ & $6.0(2)$ \\
\hline $\mathrm{C} 8$ & $0.2778(5)$ & $0.1117(3)$ & $0.4987(3)$ & $3.8(1)$ \\
\hline
\end{tabular}

a Equivalent isotropic temperature factors $\left(B_{c q}=4 / 3\left\{\Sigma \Sigma B_{i f} a_{i} a_{j}\right\}\right)$.

\section{7. $\mathrm{Co}_{2}\left(\mathrm{H}_{2} \mathrm{Hbab}\right)_{2}(\mathrm{~N}-\mathrm{MeIm})_{2}(2)$}

Lavender parallelepiped crystals of 2 were obtained by the slow diffusion of acetonitrile into a saturated solution of 2 in DMF over a period of 3 weeks at ambient temperature in an inert atmosphere box. Air sensitive crystals of approximate dimensions $0.70 \times$ $0.50 \times 0.25 \mathrm{~mm}$ were mounted in an inert atmosphere box in capillary tubes. Diffraction measurements were made on a four circle Rigaku AFC5S fully automated diffractometer using graphite-monochromated $\mathrm{Cu} \mathrm{K} \alpha$ $(\lambda=1.54178 \AA)$. The cell constants and an orientation matrix for data collection were obtained from a leastsquares refinement using the setting angles of 22 carefully centered reflections in the range $40.61<2 \theta<55.51^{\circ}$ and corresponded to a triclinic cell with dimensions: $a=10.012(2), b=12.830(2), \quad c=$ 9.948(2) $\AA, \alpha=93.67(2), \quad \beta=119.02(1), \quad$ and $\gamma=$ $96.42(2)^{\circ}$. Based on packing considerations, a statistical analysis of intensity distribution, and the successful solution and refinement of the structure, the space group was determined to be $P 1$ (no. 2), $Z=2$, with one molecule of the compound forming the asymmetric unit. The volume was $1100.0(4) \dot{\mathrm{A}}^{3}$ and the calculated density was $1.471 \mathrm{~g} \mathrm{~cm}^{-3}$. The compound is a dimer, the monomeric unit cell comprises the asymmetric unit and the dimer is formed through utilization of the inversion center.

There were 3281 unique reflections collected with $2 \theta$ $120^{\circ}$; of those reflections, 1631 with $I<3 \sigma(I)$ were adjudged observed. Scans of $(1.68+0.30 \tan \theta)^{\circ}$ were made at a speed of $8.0^{\circ} \mathrm{min}^{-1}$ (in omega). The weak reflections $(I<10.0 \sigma(I))$ were rescanned (a maximum of 2 rescans) and the counts were accumulated to assure good counting statistics. The data were corrected for Lorentz and polarization effects. The linear absorption coefficient for $\mathrm{Cu} \mathrm{K} \alpha$ is $67.28 \mathrm{~cm}^{-1}$. An empirical absorption correction, based on azimuthal scans of three reflections was applied which resulted in transmission factors ranging from 0.33 to 1.00 .

The structure was solved using MITHRIL [15] where the cobalt was located and subsequent DIRDIF [15] revealed the entire non-hydrogen structure. The cobalt atom was also located in the Patterson [15]. The following hydrogens $\mathrm{H} 2 *, \mathrm{H} 3, \mathrm{H} 1, \mathrm{H} 2, \mathrm{H} 16, \mathrm{H} 17, \mathrm{H} 19, \mathrm{H} 21$, $\mathrm{H} 23 \mathrm{a}, \mathrm{H} 23 \mathrm{~b}, \mathrm{H} 23 \mathrm{c}$ and $\mathrm{H} 24$ were located on difference Fourier maps. The rest of the hydrogens were calculated and assigned isotropic thermal parameters which were $20 \%$ greater than the equivalent value of the atom to which they were bonded.

The final cycle of full-matrix least-squares anisotropic refinement was based on 1631 observed reflections $I 3 \sigma(I)$ and 298 variable parameters. The refinement converged with the conventional crystallographic values of $R=0.051$ and $R_{\mathrm{w}}=0.049$. The standard deviation of an observation of unit weight was 1.35. The weighting scheme was based on counting statistics and included a factor $(p=0.03)$ to downweight the intense reflections. The maximum and minimum peaks on the final difference Fourier map corresponded to 0.36 and -0.33 e $\AA^{-3}$. All calculations were performed using the TEXSAN [19] crystallographic software package. Some details of the crystallographic data are given in Table 1, positional parameters for important atoms are given in Table 4, and selected bond distances and angles are provided in Table 5.

Table 3

Interatomic distances $(\dot{\mathrm{A}})$ and angles $\left(^{\circ}\right)$ for $1^{\text {a }}$

\begin{tabular}{llll}
\hline Bond lengths & & & \\
Co-Cl1 & $2.251(1)$ & N2-C4 & $1.336(4)$ \\
Co-Cl2 & $2.248(1)$ & N3-C5 & $1.365(5)$ \\
Co-N1 & $2.004(3)$ & N3-C8 & $1.317(4)$ \\
Co-N3 & $2.007(3)$ & N4-C6 & $1.350(5)$ \\
N1-C1 & $1.382(4)$ & N4-C7 & $1.465(5)$ \\
N1-C4 & $1.322(4)$ & N4-C8 & $1.328(5)$ \\
N2-C2 & $1.360(5)$ & C1-C2 & $1.338(5)$ \\
N2-C3 & $1.460(5)$ & C5-C6 & $1.343(6)$ \\
Bond angles & & & \\
C11-Co-Cl2 & $117.94(5)$ & Co-N3-C5 & $125.5(3)$ \\
C11-Co-N1 & $111.09(9)$ & Co-N3-C8 & $128.1(3)$ \\
Cl1-Co-N3 & $105.51(9)$ & C5-N3-C8 & $126.6(3)$ \\
C12-Co-N1 & $103.42(8)$ & C6-N4-C7 & $105.2(3)$ \\
Cl2-Co-N3 & $108.3(1)$ & C6-N4-C8 & $126.2(3)$ \\
N1-Co-N3 & $110.6(1)$ & C7-N4-C8 & $107.4(3)$ \\
Co-N1-C1 & $128.2(1)$ & N1-C1-C2 & $108.9(3)$ \\
Co-N1-C4 & $126.0(1)$ & N2-C2-C1 & $107.4(3)$ \\
C1-N1-C4 & $126.0(2)$ & N1-C4-N2 & $111.1(3)$ \\
C2-N2-C3 & $105.5(3)$ & N3-C5-C6 & $109.5(4)$ \\
C2-N2-C4 & $127.3(3)$ & N4-C6-C5 & $106.6(4)$ \\
C3-N2-C4 & $107.1(3)$ & N3-C8-N4 & $111.3(3)$ \\
\hline
\end{tabular}

\footnotetext{
${ }^{a}$ Estimated standard deviations in the least significant figure are given in parentheses.
} 
Table 4

Positional parameters and equivalent isotropic temperature factors for the non-hydrogen atoms of $\mathrm{Co}_{2}{ }^{2+}\left(\mathrm{H}_{2} \mathrm{Hbab}\right)_{2}(\mathrm{~N}-\mathrm{MeIm})_{2}(2)^{a}$

\begin{tabular}{|c|c|c|c|c|}
\hline Atom & $x$ & $y$ & 2 & $B_{\text {eq }}\left(\dot{A}^{2}\right)$ \\
\hline Col & $0.39852(14)$ & $0.569154(82)$ & $0.02996(15)$ & $2.92(5)$ \\
\hline $\mathrm{O} 1$ & $0.51152(66)$ & $0.66383(31)$ & $0.22565(55)$ & $3.4(2)$ \\
\hline $\mathrm{O} 2$ & $0.66661(62)$ & $0.98842(36)$ & $0.36362(65)$ & $5.8(3)$ \\
\hline $\mathrm{O} 3$ & $0.31496(52)$ & $0.70866(31)$ & $-0.06648(55)$ & $3.1(2)$ \\
\hline O4 & $0.50078(54)$ & $0.56885(31)$ & $-0.09331(54)$ & $3.3(2)$ \\
\hline $\mathrm{NI}$ & $0.47230(75)$ & $0.86045(41)$ & $0.19829(74)$ & $3.5(3)$ \\
\hline N2 & $0.36599(67)$ & $0.86939(41)$ & $-0.12358(68)$ & $3.4(3)$ \\
\hline N3 & $0.17637(68)$ & $0.49652(43)$ & $-0.06945(71)$ & $3.5(3)$ \\
\hline N4 & $-0.02729(82)$ & $0.37165(49)$ & $-0.16034(84)$ & $4.6(3)$ \\
\hline $\mathrm{Cl}$ & $0.66164(91)$ & $0.70029(53)$ & $0.31806(85)$ & $3.0(3)$ \\
\hline $\mathrm{C} 2$ & $0.77252(97)$ & $0.63241(55)$ & $0.36997(90)$ & $3.8(3)$ \\
\hline $\mathrm{C} 3$ & $0.9268(10)$ & $0.66960(65)$ & $0.4675(10)$ & $5.1(4)$ \\
\hline $\mathrm{C4}$ & $0.9778(11)$ & $0.77701(72)$ & $0.5195(11)$ & $6.6(5)$ \\
\hline C5 & $0.8718(11)$ & $0.84496(58)$ & $0.4701(10)$ & $5.6(4)$ \\
\hline C6 & $0.71511(93)$ & $0.81125(52)$ & $0.36976(86)$ & $3.4(3)$ \\
\hline C7 & $0.6164(10)$ & $0.89462(55)$ & $0.31301(97)$ & $3.8(3)$ \\
\hline $\mathrm{C} 8$ & $0.36296(88)$ & $0.92735(53)$ & $0.1135(11)$ & $3.5(3)$ \\
\hline $\mathrm{C} 9$ & $0.3152(10)$ & $0.99241(62)$ & $0.1939(10)$ & $4.9(4)$ \\
\hline $\mathrm{C} 10$ & $0.2125(12)$ & $1.06013(70)$ & $0.1123(15)$ & $6.9(5)$ \\
\hline $\mathrm{Cl1}$ & $0.1581(12)$ & $1.06117(75)$ & $-0.0438(15)$ & $7.2(5)$ \\
\hline $\mathrm{C} 12$ & $0.2042(10)$ & $0.99465(61)$ & $-0.1204(10)$ & $5.3(4)$ \\
\hline $\mathrm{C} 13$ & $0.30680(89)$ & $0.92656(53)$ & $-0.0432(11)$ & $3.6(3)$ \\
\hline $\mathrm{Cl} 4$ & $0.36597(80)$ & $0.76287(52)$ & $-0.13580(86)$ & $3.0(3)$ \\
\hline $\mathrm{Cl5}$ & $0.42735(77)$ & $0.72077(51)$ & $-0.23280(85)$ & $2.8(3)$ \\
\hline $\mathrm{Cl} 6$ & $0.42379(90)$ & $0.77045(52)$ & $-0.35304(96)$ & $3.8(3)$ \\
\hline $\mathrm{Cl} 7$ & $0.48397(95)$ & $0.73562(58)$ & $-0.44323(93)$ & $4.1(3)$ \\
\hline $\mathrm{Cl} 18$ & $0.54656(99)$ & $0.64398(59)$ & $-0.4139(10)$ & $4.6(4)$ \\
\hline $\mathrm{C} 19$ & $0.55027(90)$ & $0.58911(52)$ & $-0.29871(91)$ & $3.6(3)$ \\
\hline $\mathbf{C} 20$ & $0.49013(81)$ & $0.62429(50)$ & $-0.20585(87)$ & $2.9(3)$ \\
\hline $\mathrm{C} 21$ & $0.0464(10)$ & $0.53276(61)$ & $-0.1767(10)$ & $4.9(4)$ \\
\hline $\mathrm{C} 22$ & $-0.0814(10)$ & $0.45588(70)$ & $-0.2342(11)$ & $5.4(4)$ \\
\hline $\mathrm{C} 23$ & $-0.1228(10)$ & $0.27152(63)$ & $-0.1814(12)$ & $7.5(5)$ \\
\hline C24 & $0.1251(10)$ & $0.39788(59)$ & $-0.0661(10)$ & $4.6(4)$ \\
\hline
\end{tabular}

a Equivalent isotropic temperature factors $\left(B_{\mathrm{eq}}=4 / 3\left\{\Sigma \Sigma B_{i j} a_{i} a_{j}\right\}\right)$.

\subsection{Physical methods}

All measurements were performed under strictly anaerobic conditions. Electronic absorption spectra were measured on a Perkin-Elmer Lambda $4 \mathrm{C}$ spectrophotometer in the $280-900 \mathrm{~nm}$, while infrared spectra were collected in a $\mathrm{KBr}$ pellet on a Nicolet 5SX FT-IR spectrometer. ' $\mathrm{H}$ NMR spectra were recorded on a GE QE-Plus $300 \mathrm{MHz}$ spectrometer. Solution susceptibility measurements were performed by standard NMR methods using mesitylene ( $2 \%$ in DMSO) as the standard. All calculations involved a correction for solvent susceptibility based on literature values [20]. Cyclic voltammetry electrochemical experiments were carried out with a standard Bioanalytical system (CV-27 voltamograph, C-1A Cell stand, BAS-RXY Recorder) with the use of a Pt or a glassy carbon working electrode, an $\mathrm{Ag}$ wire reference electrode, and $0.1 \mathrm{M}$ tetra-n-butylammonium tetrafluoroborate (TBAT) as supporting elec- trolyte. All electrochemical studies were conducted at ambient temperature in an inert atmosphere $\left(\mathrm{N}_{2}\right)$ box. The $\mathrm{Fe}(0 /+)$ couple of ferrocene $(E=0.400 \mathrm{~V}$ versus NHE) was used as an internal standard [21]. EPR spectra were recorded on a JEOL ME-3X X-band EPR spectrometer equipped with an Oxford ESR-900 liquid Helium cryostat. Sample temperatures were determined with a carbon glass resistor (Lake Shore Cryotronics) contained in a sample tube in the sample position [22].

Catalytic reactions were carried out under anaerobic conditions. All gas chromatographic analysis were performed on a Hewlett Packard Series 2 GC equipped with an analytical methyl silicon capillary column (50 $\mathrm{m} \times 0.25 \mathrm{~mm}$ i.d.) and interfaced to a HP3396 series II integrator. Gradient temperature programs were used for baseline resolution. When iodosylbenzene was used as the oxo-atom donor, iodobenzene was recovered in quantitative yields. Best catalytic results were obtained when OIPh was added in 3 equiv. aliquots over the first $3 \mathrm{~h}$. Parallel control reactions (OIPh and substrate) were performed in all cases; products were verified through the use of authentic samples and GC/MS analysis using a HP5890 Series II instrument equipped with a HP 5971A mass selective detector. Products were quantified using chlorobenzene as an internal standard. In catalytic reactions utilizing tert-butyl hydroperoxide, excess peroxide was quenched prior to $\mathrm{GC}$ or $\mathrm{GC} / \mathrm{MS}$ analysis by using triphenyl phosphine. The experimental details for catalytic reactions with 5 have already been reported [8]. A summary of the data for the catalytic trials is reported in Table 6.

\section{Results and discussion}

\subsection{Synthesis}

Towards continuing our interest in understanding the chemistry of binuclear metal systems capable of oxygen atom transfer catalysis $[8,9]$, we have synthesized a lavender-colored binuclear $\mathrm{Co}^{2+}$ compound, $\left[\mathrm{Co}_{2}{ }^{2+}\right.$ $\left.\left(\mathrm{H}_{2} \mathrm{Hbab}\right)_{2}(N-\mathrm{MeIm})_{2}\right]$ (2), by the reaction of 1 equiv. of $\mathrm{Co}(\mathrm{Cl})_{2}(\mathrm{~N}-\mathrm{MeIm})_{2}(1)$, with 1 equiv. of $\mathrm{Li}_{2} \mathrm{H}_{2} \mathrm{Hbab}$ in methanol. We have found that 1 is a facile synthon for the introduction of a $\mathrm{Co}^{2+}(N$-MeIm) moiety into a complex with the added features that it is easy to prepare, is air stable, and it exhibits high solubility in a variety of organic solvents. The synthesis of $\left[\mathrm{Co}_{2}{ }^{2+}\left(\mathrm{H}_{2} \mathrm{Hbab}\right)_{2}(\mathrm{~N} \text {-MeIm })_{2}\right]$ uses methods analogous to those previously reported for the synthesis of the binuclear ferrous complex, $\left[\mathrm{Fe}_{2}{ }^{2+}\left(\mathrm{H}_{2} \mathrm{Hbab}\right)_{2}(\mathrm{~N}\right.$ $\left.\mathrm{MeIm})_{2}\right](5)[8,9]$. The solubility properties of 2 and $\mathbf{5}$ are similar with both being practically insoluble in most common organic solvents, but fairly soluble in DMF and DMSO $(40 \mathrm{mM})$. Unlike 5 , however, which has a limiting solubility in $\mathrm{MeOH}(0.5 \mathrm{mM}), 2$ exhibits no 
appreciable solubility in alcoholic solvents, precluding the use of anaerobic isothermal distillation techniques to establish its solution nuclearity $[8,9]$. It is stable in anaerobic DMF solutions; less than $2 \%$ decomposition is observed by optical methods over a $12 \mathrm{~h}$ period. The green mixed-valence complex $\left[\mathrm{Co}^{2}+\mathrm{Co}^{3+}\left(\mathrm{H}_{2} \mathrm{Hbab}\right)_{2}-\right.$ $\left.(\mathrm{N} \text {-MeIm })_{2}\right]^{+}(3)$ and the green-brown fully oxidized $\mathrm{Co}^{3+}$ complex $\left[\mathrm{Co}_{2}{ }^{3+}\left(\mathrm{H}_{2} \mathrm{Hbab}\right)_{2}(N-\mathrm{MeIm})_{2}\right]^{2+}$ (4), were both cleanly synthesized by $\mathrm{I}_{2}$ oxidation of 2 . Both 3 and 4 are soluble in DMF and DMSO and stable to decomposition. In all cases, complexes 2-4 afforded satisfactory elemental analyses after vacuum drying.

\subsection{Solution and solid-state structure of $\mathrm{Co}(\mathrm{N}-\mathrm{MeIm})_{2}(\mathrm{Cl})_{2}(1)$}

Compounds of the type CoX $\mathrm{amine}_{2}$ are known to exist as either violet or blue species [23]. More recent studies have shown that two stereochemical arrangements are responsible for these distinct products; the violet compounds corresponding to an octahedral, polymeric chain structure while the blue form adopting a tetrahedral, monomeric structure [24]. The equilibrium between these forms is temperature-, pressureand solvent-dependent with the tetrahedral form stabilized by high temperatures and low pressures [25].

The low ratio of $N$-MeIm to $\mathrm{Co}^{2+}$ used in the synthesis of 1 is expected to favor the production of monomeric products [24]. The electronic spectrum of 1 in DMF (Fig. 1) shows the presence of the ${ }^{4} A_{2} \rightarrow{ }^{4} T_{1}(P)$ transitions between 575 and $630 \mathrm{~nm}$ with molar extinction coefficients consistent with a tetrahedral geometry
[26]. This absorption band consists of three components whose overall width is analogous to that reported for the corresponding absorption in the tetrahedral $\left[\mathrm{CoX}_{4}\right]^{2-}$, suggesting little evidence of any $C_{20}$ perturbation $[26,27]$. This is in agreement with solution magnetic susceptibility measurements which gave a value of 4.27 $\mathrm{BM}$, within the range typically observed for tetrahedral $\mathrm{Co}^{2+}$ complexes (3.98-4.82 BM) $[28,29]$.

The solid-state structure of 1 (Fig. 2) shows $\mathrm{Co}^{2+}$ to be tetrahedrally coordinated; the bond lengths and angles in the molecule are normal within the observed standard deviations of the few tetrahedral $\mathrm{CoA}_{2} \mathrm{X}_{2}$ compounds that have been characterized and are different from the polymeric six-coordinate violet form of $\mathrm{CoPy}_{2} \mathrm{Cl}_{2}[24,29]$. The somewhat shorter $\mathrm{Co}-\mathrm{N} 1(2.004$ $\AA)$ and $\mathrm{Co}-\mathrm{N} 3(2.007 \AA)$ bond lengths of 1 versus those reported for the 4-methylpyridine complex $(2.03$ and $2.06 \AA$ ) reflect the greater basicity of the $N$-MeIm ligand $\left(\mathrm{p} K_{\mathrm{a}}=7.06\right)$ versus $4-\mathrm{MePy}\left(\mathrm{p} K_{\mathrm{a}}=5.25\right)$ [30]. However, the largest variations in the $\mathrm{CoA}_{2} \mathrm{Cl}_{2}$ structures are observed to occur in the $\mathrm{N}-\mathrm{Co}-\mathrm{N}$ angles that appear to depend intimately on the stereochemical requirements of the nitrogen heterocycles. In the unrestricted 4-substituted pyridine compounds, the $\mathrm{N}-\mathrm{Co}-\mathrm{N}$ angle is close to the idealized tetrahedral value (4-vinylpyridine [31], $107^{\circ}$; 4-methylpyridine [30], $107^{\circ}$ ) while the structures with bulky 2-substituents show an expanded angle (2-methoxypyridine [32], 114 ${ }^{\circ}$. A structure with a seven-membered chelate ring, [bis(2-pyridyl)disulfide] $\mathrm{CoCl}_{2}$ [33], contains a significantly expanded $\mathrm{N}-\mathrm{Co}-\mathrm{N}$ angle of $118^{\circ}$ while the six-

Table 5

Comparison of selected interatomic distances $(\dot{A})$ and angles $\left(^{\circ}\right)$ for isostructural $\mathrm{Co}_{2}{ }^{2+}\left(\mathrm{H}_{2} \mathrm{Hbab}_{2}(\mathrm{~N} \cdot \mathrm{MeIm})_{2}(2)\right.$ and $\mathrm{Fe}{ }_{2}{ }^{2+}\left(\mathrm{H}_{2} \mathrm{Hbab}\right)_{2}(N$. $\mathrm{MeIm})_{2}(\mathbf{5})$

\begin{tabular}{|c|c|c|c|c|c|}
\hline & 2 & 5 & & 2 & 5 \\
\hline \multicolumn{6}{|l|}{ Distances } \\
\hline $\mathrm{M}-01$ & $1.949(5)$ & $1.948(7)$ & $\mathrm{O} 2-\mathrm{C} 7$ & $1.223(7)$ & $1.24(1)$ \\
\hline $\mathrm{M}-\mathrm{O} 3$ & $2.145(4)$ & $2.150(7)$ & $\mathrm{O} 3-\mathrm{Cl}$ & $1.242(7)$ & $1.24(1)$ \\
\hline M-O4 & $1.942(5)$ & $1.997(7)$ & $\mathrm{O} 4-\mathrm{C} 20$ & $1.332(8)$ & $1.32(1)$ \\
\hline $\mathrm{M}-\mathrm{O4^{ \prime }}$ & $2.115(4)$ & $2.167(7)$ & N1-C7 & $1.332(9)$ & $1.33(1)$ \\
\hline M-N3 & $2.019(6)$ & $2.080(9)$ & $\mathrm{N1}-\mathrm{C} 8$ & $1.433(9)$ & $1.41(1)$ \\
\hline $\mathbf{M}-\mathbf{M}^{\prime}$ & $3.079(2)$ & $3.165(7)$ & $\mathrm{N} 2-\mathrm{C} 13$ & $1.418(9)$ & $1.43(1)$ \\
\hline O4-O4' & $2.648(9)$ & & $\mathrm{N} 2-\dot{\mathrm{C}} 14$ & $1.364(8)$ & $1.36(1)$ \\
\hline $\mathrm{O} 1-\mathrm{Cl}$ & $1.330(8)$ & $1.35(1)$ & & & \\
\hline \multicolumn{6}{|l|}{ Angles } \\
\hline $\mathrm{O} 1-\mathrm{M}-\mathrm{O} 3$ & $84.3(2)$ & $91.0(3)$ & $\mathrm{M}-\mathrm{Ol}-\mathrm{Cl}$ & $132.2(5)$ & $125.5(7)$ \\
\hline $\mathrm{O} 1-\mathrm{M}-\mathrm{O} 4$ & $114.5(2)$ & $117.0(3)$ & $\mathrm{M}-\mathrm{O} 3-\mathrm{Cl} 4$ & $124.8(5)$ & $127.0(7)$ \\
\hline $\mathrm{O} 1-\mathrm{M}-\mathrm{O} 4^{\prime}$ & $101.5(2)$ & $98.6(3)$ & $\mathrm{M}-\mathrm{O} 4-\mathrm{M}^{\prime}$ & $98.6(2)$ & $98.9(3)$ \\
\hline O1-M-N3 & $126.1(2)$ & $127.6(3)$ & $\mathrm{M}-\mathrm{O} 4-\mathrm{C} 20$ & $131.9(4)$ & $133.5(7)$ \\
\hline $\mathrm{O} 3-\mathrm{M}-\mathrm{O} 4$ & $86.9(2)$ & $84.6(3)$ & $\mathrm{M}-\mathrm{O} 4^{\prime}-\mathrm{C} 20^{\prime}$ & $128.4(4)$ & $127.0(7)$ \\
\hline O3-M-O4' & $168.2(2)$ & $165.3(3)$ & $\mathrm{M}-\mathrm{N} 3-\mathrm{C} 21$ & $127.3(5)$ & $128.1(8)$ \\
\hline O3-M-N3 & $88.4(2)$ & $89.4(3)$ & $\mathrm{M}-\mathrm{N} 3-\mathrm{C} 24$ & $127.7(6)$ & $128.1(9)$ \\
\hline $\mathrm{O} 4-\mathrm{M}-\mathrm{O} 4^{\prime}$ & $81.4(2)$ & $81.1(3)$ & $\mathrm{C} 7-\mathrm{N} 1-\mathrm{C} 8$ & $125.0(6)$ & $122.1(9)$ \\
\hline O4-M-N3 & $118.3(2)$ & $115.2(3)$ & $\mathrm{C} 13-\mathrm{N} 2-\mathrm{C} 14$ & $126.5(6)$ & $123(1)$ \\
\hline $\mathrm{O}^{\prime}-\mathrm{M}-\mathrm{N} 3$ & $96.2(2)$ & $93.5(3)$ & & 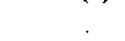 & \\
\hline
\end{tabular}


Table 6

Catalytic oxidations of organic substrates by $\left[\mathrm{M}^{\mathrm{n}+}, \mathrm{M}^{\mathrm{m}+}\right]$ complexes

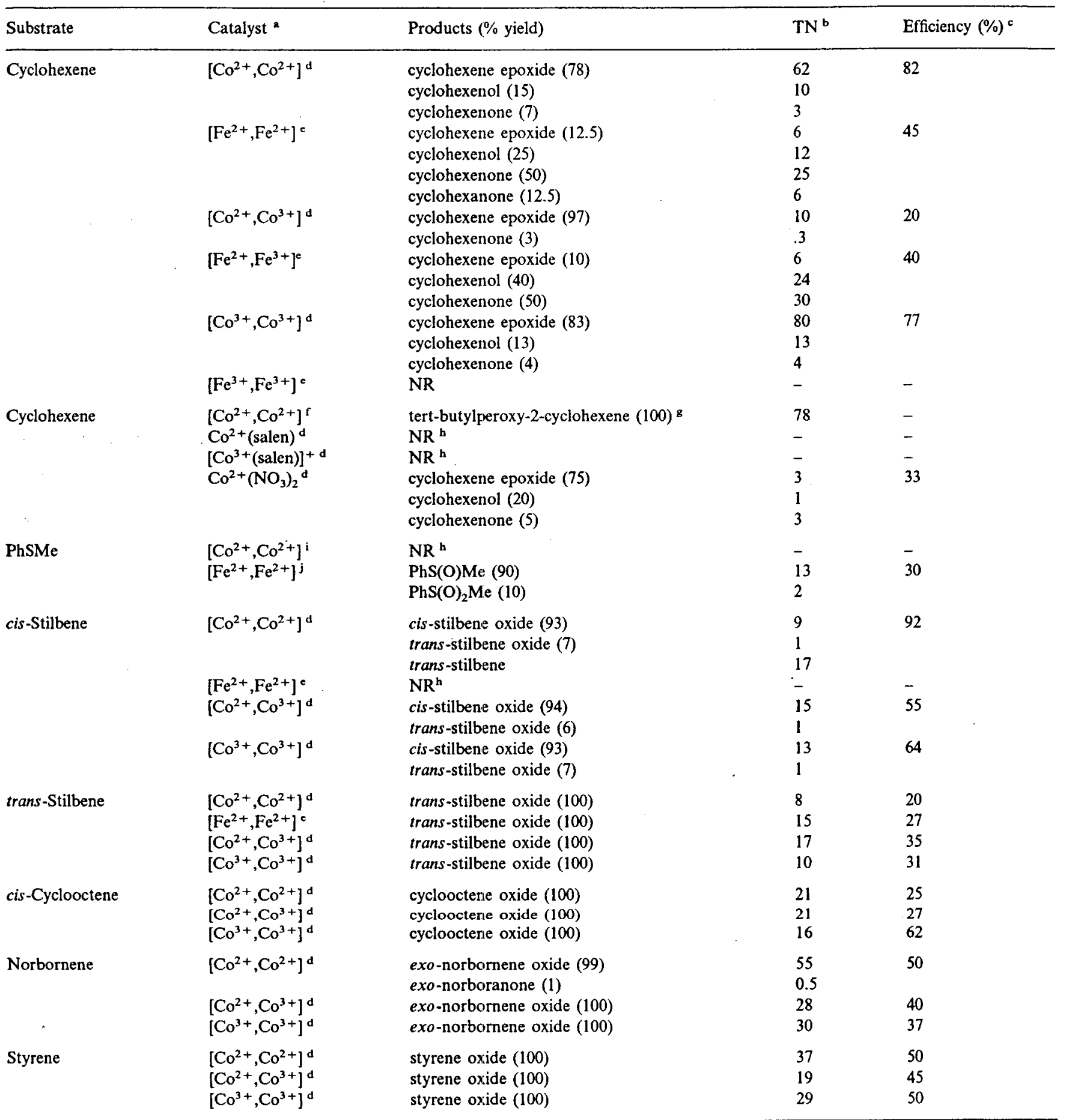

a $\left[\mathrm{Co}^{2+}, \mathrm{Co}^{2+}\right](2), \mathrm{Co}_{2}{ }^{2+}\left(\mathrm{H}_{2} \mathrm{Hbab}\right)_{2}(N-\mathrm{MeIm})_{2} ;\left[\mathrm{Co}^{2+}, \mathrm{Co}^{3+}\right](3),\left[\mathrm{Co}^{2+} \mathrm{Co}^{3+}\left(\mathrm{H}_{2} \mathrm{Hbab}\right)_{2}(N-\mathrm{MeIm})_{2}\right]^{+} ;\left[\mathrm{Co}^{3+}, \mathrm{Co}^{3+}\right](4)\left[\mathrm{Co}_{2}^{3+}\left(\mathrm{H}_{2} \mathrm{Hbab}_{2}(N-\right.\right.$ $\left.\mathrm{Melm})_{2}\right]^{2+} ; \quad\left[\mathrm{Fe}^{2+}, \mathrm{Fe}^{2+}\right] \quad(5), \quad \mathrm{Fe}_{2}{ }^{2+}\left(\mathrm{H}_{2} \mathrm{Hbab}\right)_{2}(\mathrm{~N}-\mathrm{MeIm})_{2} ; \quad\left[\mathrm{Fe}^{2+}, \mathrm{Fe}^{3+}\right] \quad(6), \quad\left[\mathrm{Fe}^{2+} \mathrm{Fe}^{3+}\left(\mathrm{H}_{2} \mathrm{Hbab}_{2}\left(\mathrm{~N}-\mathrm{MeIm}_{2}\right]^{+} ; \quad\left[\mathrm{Fe}^{3+}, \mathrm{Fe}^{3+}\right] \quad(7)\right.\right.$, $\left[\mathrm{Fe}_{2}{ }^{3+}\left(\mathrm{H}_{2} \mathrm{Hbab}\right)_{2}(\mathrm{~N}-\mathrm{MeIm})_{2}\right]^{2+}$.

${ }^{b} \mathrm{TN}$ is the (moles of product from catalyzed reaction-moles of product from control (uncatalyzed) reaction)/moles of catalyst.

c $100 \%$ efficiency represents one substrate oxidation per iodosylbenzene consumed.

${ }^{d}$ Ratio of catalyst:PhIO:substrate was 1:120:600, [catalyst] $=1,00 \mathrm{mM}$. Reactions were followed over a $12 \mathrm{~h}$ period.

e Ratio of catalyst:PhIO:substrate was $1: 2 \times 10^{3}: 1 \times 10^{4}$, [catalyst] $=0.05 \mathrm{mM}$. Reactions were followed over a $6 \mathrm{~h}$ time period.

${ }^{\mathrm{f}}$ Ratio of catalyst:tert-butyl hydroperoxide:substrate $=1: 120: 2500$, [catalyst] $=1 \mathrm{mM}$. Reactions were followed over a $12 \mathrm{~h}$ period.

8 Products did not include any cyclohexene epoxide, cyclohexenone and cyclohexenol.

${ }^{\text {h }} \mathrm{NR}$, No reaction, $2 \%$ substrate oxidation.

${ }^{i}$ Ratio of catalyst:PhIO:substrate was $1: 200: 1000$, [catalyst] $=0.05 \mathrm{mM}$.

j Ratio of catalyst:PhlO:substrate was 1:250:5000, [catalyst] $=0.001 \mathrm{mM}$. 
membered ring found in the [phenyldi(2-pyridyl)phosphine- $N-N^{\prime}$ ] $\mathrm{CoCl}_{2}$ compound [34] gives rise to a $\mathrm{N}-\mathrm{Co}-\mathrm{N}$ angle of $95^{\circ}$. The current $\mathrm{N}-\mathrm{Co}-\mathrm{N}$ angle of $110.6^{\circ}$ in 1 is consistent with those reported for the unrestricted 4-substituted pyridine analogs as expected for the sterically undemanding $N$-MeIm moiety.

\subsection{Solid-state structure of \\ $\mathrm{Co}_{2}{ }^{2+}\left(\mathrm{H}_{2} \mathrm{Hbab}\right)_{2}(\mathrm{~N} \text {-MeIm })_{2}$ (2) and comparison to \\ $\mathrm{Fe}_{2}{ }^{2+}\left(\mathrm{H}_{2} \mathrm{Hbab}\right)_{2}(\mathrm{~N}-\mathrm{MeIm})_{2}$ (5)}

While the $\mathrm{H}_{2} \mathrm{Hbab}^{2}$ - ligand is capable of forming both mononuclear [10] and binuclear metal complexes $[8,9]$, our synthetic scheme for the $\mathrm{Fe}^{2+}$ and $\mathrm{Co}^{2+}$ metal centers exclusively afforded binuclear complexes in high yields (Scheme 2). As was previously reported for the diferrous complex 5 [9], the structure of 2 shows

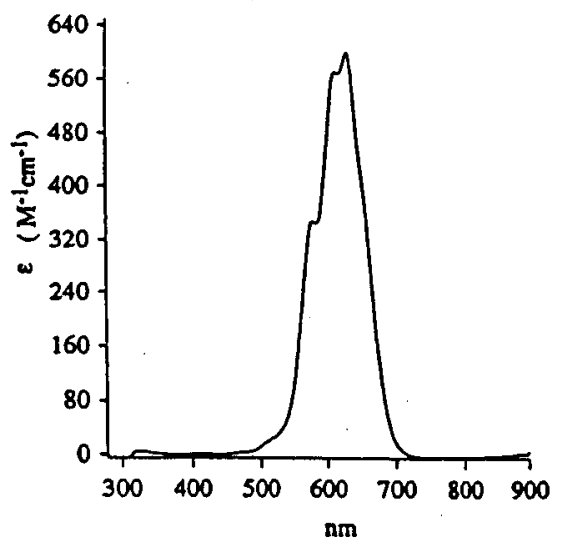

Fig. 1. Electronic absorption spectrum of $\mathrm{XX} \mathrm{M} \mathrm{Co}{ }^{2+}(N$. MeIm $)_{2}(\mathrm{Cl})_{2}$ in DMF showing the $d-d$ transitions for the four coordinate $d^{7}$ metal ion.

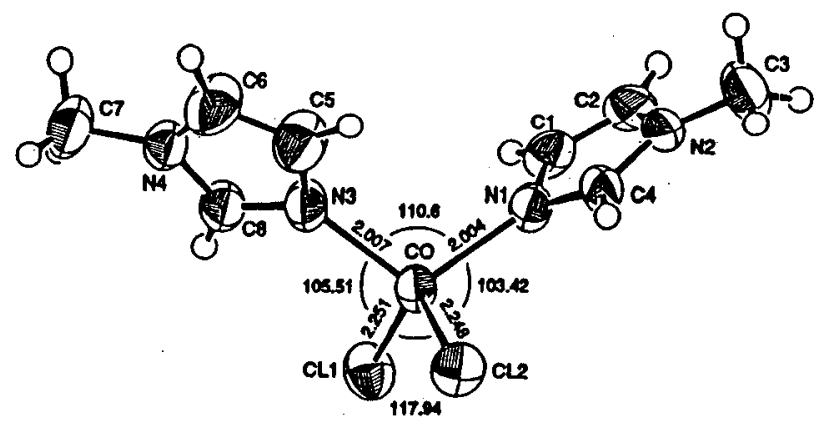

Fig. 2. ORTEP view of the molecule $\mathrm{Co}^{2}+(\mathrm{N}-\mathrm{MeIm})_{2}(\mathrm{Cl})_{2}$ (1). Thermal ellipsoids are drawn at the $50 \%$ probability level.
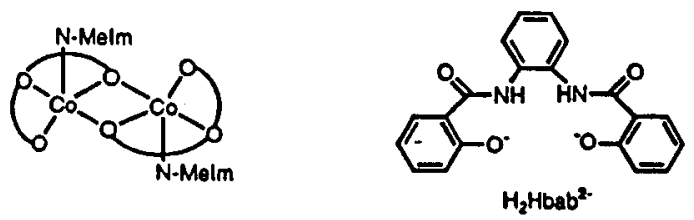

Scheme 2. two trigonal bipyramidal $\mathrm{Co}^{2+}$ atoms sharing a common axial-equatorial edge with the two metal centers bridged by two $\mathrm{H}_{2} \mathrm{Hbab}^{2}$ - ligands (Fig. 3). Each $\mathrm{Co}^{2+}$ atom is bridged by two phenolate oxygen atoms of different $\mathrm{H}_{2} \mathrm{Hbab}^{2-}$ ligands. This type of doubly bridged core structure, although represented in both ferric and ferrous complexes [9], is limited to the well known family of structurally characterized six-coordinate bis- $\mu$-hydroxy $\mathrm{Co}^{3+}$ complexes [35]. Compound 2, however, represents the first bis- $\mu$-phenolate $\mathrm{Co}^{2+}$ core that has been structurally characterized; the other systems containing binucleating ligands being the six-coordinate $\mathrm{Co}^{3+} \mu$-phenoxy-bis- $\mu$-acetate bridged Bpmpsystem, $\left[\mathrm{Co}^{3+}(\mathrm{Bpmp})(\mu \text {-benzoate })\left(\mathrm{O}_{2}\right)\right]^{2+}[36]$, and the mixed phenol and pyridine podand containing Bhpmp complex, $\left[\mathrm{Co}^{3+}(\mathrm{Bhpmp})(\mu \text {-proponiate })_{2}\right]^{+}$[37]. In addition to the bridging phenolate oxygen atoms, each $\mathrm{Co}^{2+}$ center is coordinated to an amide oxygen of the same benzamido moiety forming a six-membered chelate ring, an additional phenolate oxygen atom from the adjacent benzamido moiety and a single $N$-MeIm yielding five-coordinate $\mathrm{NO}_{4}$ ligand donor sets about each $\mathrm{Co}^{2+}$ center. The two metal centers are related by a crystallographically imposed center of symmetry.

Analysis of the Co coordination spheres in 2 using the conformational analysis methods of Auf der Hyde and Burgi indicate that each adopts a trigonal-bipyramidal geometry (Fig. 4) with the atoms $O(1), O(4)$ and $\mathrm{N}(3)$ forming the equatorial plane [38]. The $\mathrm{Co}^{2+}$ center is $0.035 \AA$ above this plane towards the $\mathrm{O}(4)^{\prime}$ bridging phenolate atom. As reported for the binuclear $\mathrm{Fe}^{2+}$ compound [9], the consequence of the six-membered chelate ring formed from the phenolate $\mathrm{O}(4)$ and amide $O(3)$ atoms that span equatorial and axial sites in the trigonal bipyramidal structure are minimal. The bond angles in the equatorial planes are as expected and show a maximum deviation from their idealized value of only $5-7^{\circ}$ while the equatorial to axial angles deviate by $5-6^{\circ}$ for $O(3)$ and $6-11^{\circ}$ for $O\left(4^{\prime}\right)$. The greater deviation of the latter center most likely reflects the constraints of the four membered $\mathrm{Co}_{2}{ }^{2+} \mathrm{O}_{2}$ core structure. In addition, 2 shows variations in the angles $\mathrm{O}(4)^{\prime}-\mathrm{Co}(1)-\mathrm{O}(1)>\mathrm{O}(4)^{\prime}-\mathrm{Co}(1)-\mathrm{N}(3)>\mathrm{O}(4)^{\prime}-\mathrm{Co}(1)-$ $\mathrm{O}(4)$ which is consistent with a tilt of the axis $\left(\mathrm{Co}(1)-\mathrm{O}(4)^{\prime}\right.$ bond) with respect to the equatorial plane in the direction of the $O(4)$ atom. A similar phenomenon was observed in 5 [9].

The crystal structure of 2 also shows that the $\mathrm{Co}-\mathrm{O}_{\text {axial }}$ bonds are longer than those of the $\mathrm{Co}-\mathrm{O}_{\text {equatorial }}$ bonds. The tight binding of the anionic terminal phenolate oxygen atoms is evident by a comparison of the observed equatorial $\mathrm{Co}(1)-\mathrm{O}_{\text {phenolate }}$ bond length $(\mathrm{Co}(1)-\mathrm{O}(1), 1.949 \AA$; $\mathrm{Co}(1)-\mathrm{O}(4), 1.942$ $\AA$ ) with other structurally characterized $\mathrm{Co}^{2+}$ systems [39] (e.g. five-coordinate square pyramidal $\mathrm{Co}^{2+}$ (salen) systems show a $\mathrm{Co}^{2+}-\mathrm{O}_{\text {phenolate }}$ range of $1.90-1.95 \dot{\mathrm{A}}$ ). 
These data also show that there is no significant difference between bridging versus monodentate phenolate coordination to $\mathrm{Co}^{2+}$, although there is an observed bond length difference of approximately $0.15 \AA$ between the equatorial and longer axial $\mathrm{Co}(1)-\mathrm{O}_{\text {phenolate }}$ bond lengths. The shorter $\mathrm{Co}^{2+}-\mathrm{N}_{N \text {-Melm }}$ distance $(2.019 \AA)$ versus typical $\mathrm{Co}^{2+}-\mathrm{N}_{\text {pyridine }}$ distances $(2.13-$ $2.15 \AA$ ) is ascribed to the increased basicity of the $N$-MeIm ligand.

As depicted in Figs. 3 and 4, the axes of the two Co coordination spheres are parallel. In centrosymmetric 2 , the $\mathrm{Co}_{2}{ }^{2}+\mathrm{O}_{2}$ core is constrained as a planar rhomb with significantly different $\mathrm{Co}-\mathrm{O}$ distances $(\Delta d=0.173$ $\AA$ ) and acute O-Co-O $\left(81.4(2)^{\circ}\right)$ and obtuse $\left(98.6(2)^{\circ}\right)$ angles. The bridging phenolate rings are crystallographically constrained to be parallel in $\mathbf{2}$ while the planes of the phenolate rings are nearly parallel to the $\mathrm{Co}-\mathrm{Co}$ vector $\left(11.3^{\circ}\right)$. The Co-Co distance of 3.079(2) $\AA$ is considered too long for metal-metal bonding while the $\mathrm{O}(4)-\mathrm{O}(4)^{\prime}$ non-bonded distance is $2.648(9) \AA$. The core structure of 2 is analogous to that of 5 with the exception of somewhat shorter metal to bridging phe-
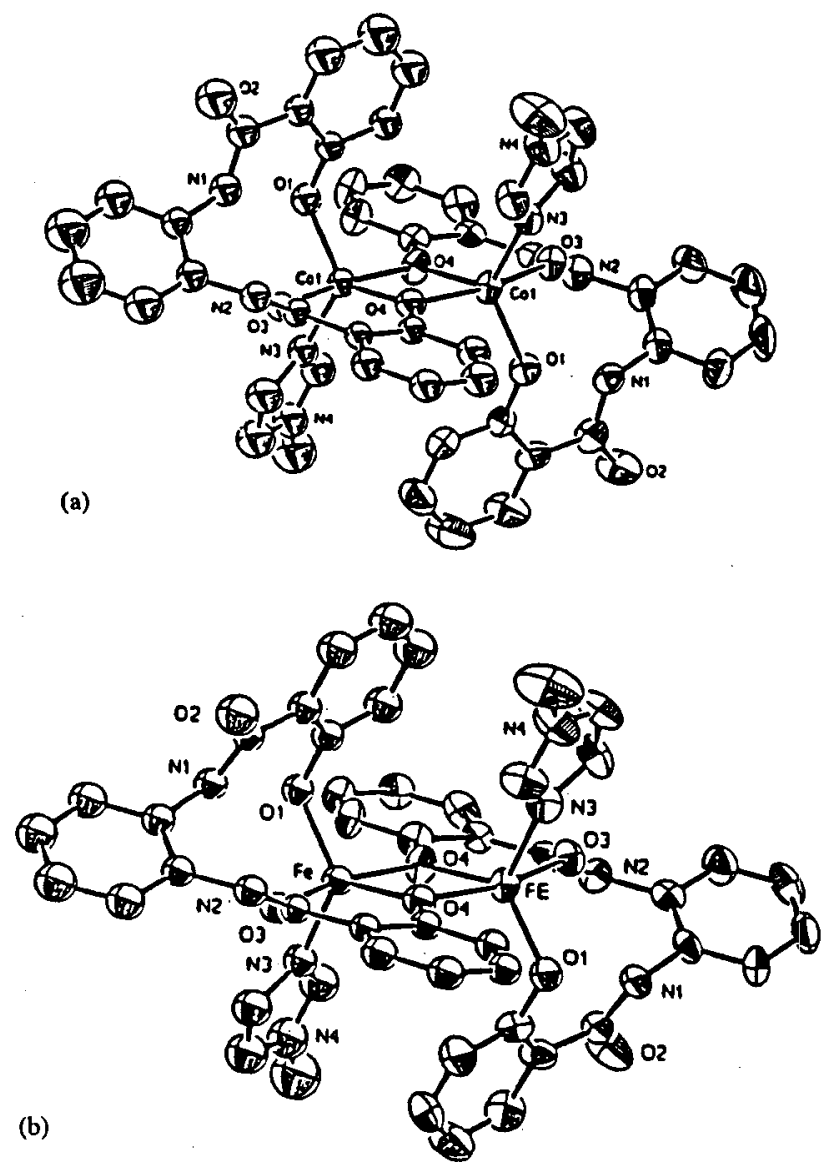

Fig. 3. ORTEP views of the isostructural molecules $\mathrm{Co}_{2}\left(\mathrm{H}_{2} \mathrm{Hbab}\right)_{2}$ ( $N$-MeIm $)_{2}$ (2); (a) and $\mathrm{Fe}_{2}\left(\mathrm{H}_{2} \mathrm{Hbab}\right)_{2}(N-\mathrm{MeIm})_{2}$ (5); (b) showing the $50 \%$ probablity thermal ellipsoids. Ligand hydrogen atoms are omitted for clarity. nolate bond lengths $\left(\Delta d_{\mathrm{Fe}-\mathrm{Co}}=0.055 \AA\right)$ for both $\mathrm{M}-\mathrm{O}(4)$ and $\mathrm{M}-\mathrm{O}(4)^{\prime}$ distances, resulting in a shorter $d_{\mathrm{M}-\mathrm{M}}$ and $d_{\mathrm{O}(4)-\mathrm{O}(4)^{\prime}}$ values (Table 5).

The topology of the $\mathrm{H}_{2} \mathrm{Hbab}^{2}$ - ligand system is significantly distorted from its expected planar nature when bound to the $\mathrm{Co}$ center. Although the $\mathrm{O}(2)-\mathrm{C}(7)-\mathrm{C}(6)-\mathrm{C}(5)$ torsion angle $\left(-7(1)^{\circ}\right)$ is near its expected planar value, the $\mathrm{C}(7)-\mathrm{N}(1)-\mathrm{C}(8)-\mathrm{C}(9)$ ( $\left.63(1)^{\circ}\right), \quad \mathrm{C}(14)-\mathrm{N}(2)-\mathrm{C}(13)-\mathrm{C}(12) \quad\left(128.8(8)^{\circ}\right), \quad$ and $\mathrm{O}(3)-\mathrm{C}(14)-\mathrm{C}(15)-\mathrm{C}(20) \quad\left(-25(1)^{\circ}\right)$ torsion angles show a more pronounced deviation from planarity. Owing to limitations of the crystallographic data that prevent the unambiguous identification of the amide proton positions in the coordinated $\mathrm{H}_{2} \mathrm{Hbab}^{2}$ - ligand, we are unable to assess the issue of planarity versus non-planarity of the amide bonds.

\subsection{Physical characterization}

The UV-Vis spectrum of 2 in DMF (Fig. 5) shows peaks at $600 \mathrm{~nm}\left(\varepsilon_{M}=160\right)$ and $540 \mathrm{~nm}\left(\varepsilon_{M}=120\right)$ in the visible region and a shoulder at $327 \mathrm{~nm}\left(\varepsilon_{\mathrm{M}}=\right.$ 23600 ). The ligand field bands at 600 and $540 \mathrm{~nm}$ are characteristic of $\mathrm{Co}^{2+}$ complexes $[26 \mathrm{~b}, 29,40]$ while the shoulder at $327 \mathrm{~nm}$ can be attributed to phenoxy to metal charge transfer band. Idealized trigonal bipyramidal spectra $\left(D_{3 h}\right.$ symmetry) are characterized by four
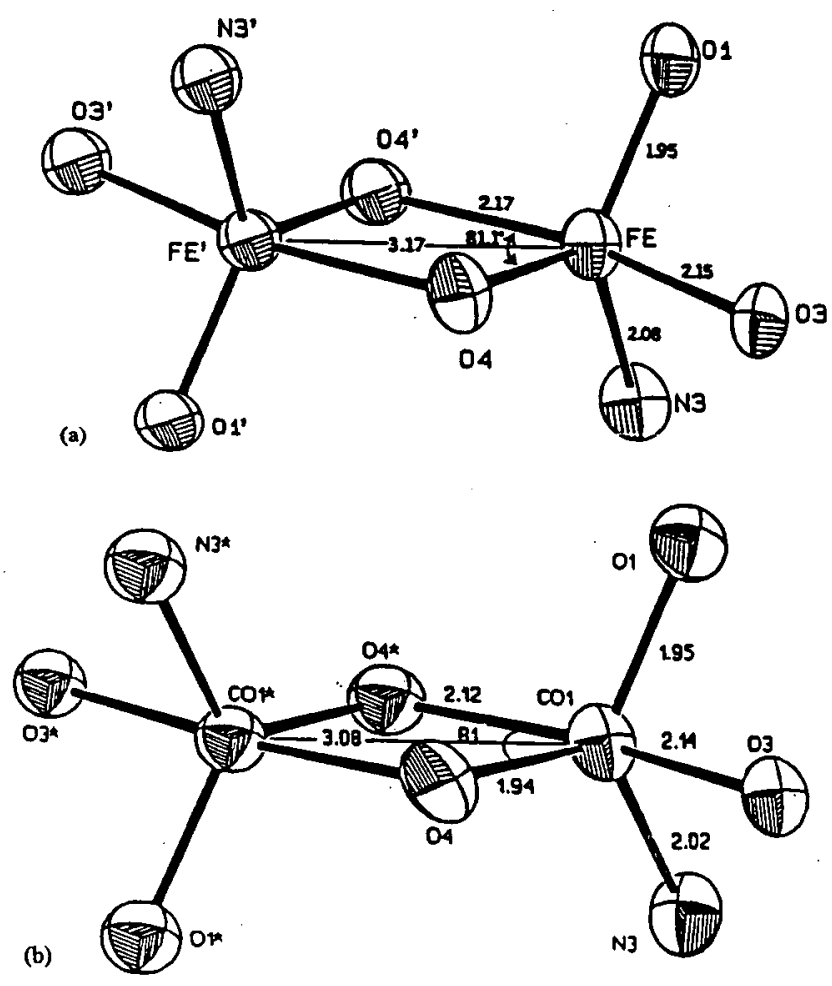

Fig. 4. ORTEP views of the primary coordination spheres of the isostructural $\mathrm{Co}_{2}\left(\mathrm{H}_{2} \mathrm{Hbab}\right)_{2}(N-\mathrm{MeIm})_{2}$ (2); (a) and $\mathrm{Fe}_{2}\left(\mathrm{H}_{2} \mathrm{Hbab}\right)_{2}$ $(\mathrm{N}-\mathrm{MeIm})_{2}$ (5), (b) molecules showing the $50 \%$ probability thermal ellipsoids. 


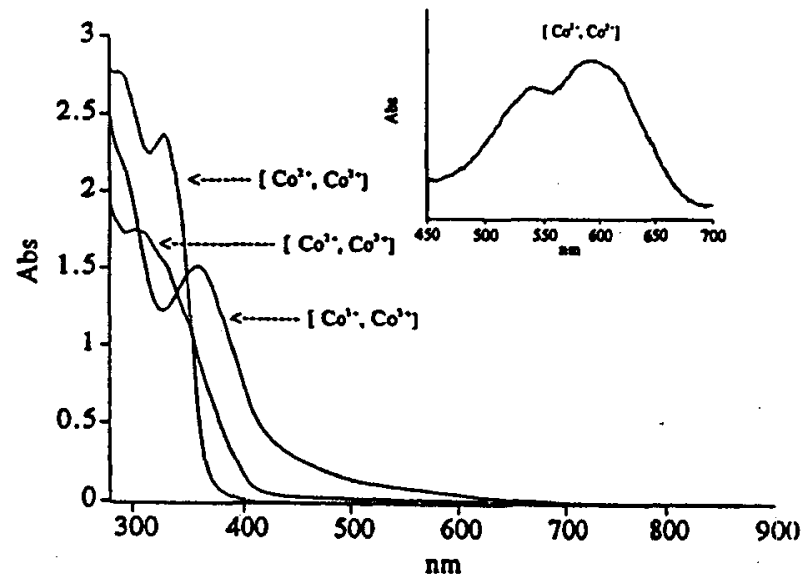

Fig. 5. Anaerobic UV-Vis spectra of $1 \mathrm{mM}$ solutions of $\left[\mathrm{Co}^{2+}\right.$, $\mathrm{Co}^{2+}$ ] (2), $\left(\lambda_{\max }\left(\varepsilon_{\mathrm{M}}\right)=600 \mathrm{~nm}(160) ; 540 \mathrm{~nm}(120) ; 327 \mathrm{~nm}(23\right.$ $600)) ;\left[\mathrm{Co}^{2+}, \mathrm{Co}^{3+}\right](3),\left(\lambda_{\max }\left(\varepsilon_{\mathrm{M}}\right)=305 \mathrm{~nm}(17400) ; 334 \mathrm{~nm}\right.$ (sh, $14500)$ ); and $\left[\mathrm{Co}^{3+}, \mathrm{Co}^{3+}\right](4),\left(\lambda_{\max }\left(\varepsilon_{\mathrm{M}}\right)=357 \mathrm{~nm}(15000)\right.$ in DMF.

bands, two of which are found in the near IR (1250$\left.2000 \mathrm{~nm},{ }^{4} \mathrm{~A}_{2}^{\prime} \rightarrow{ }^{4} \mathrm{E}^{\prime} ; 770 \sim 1000 \mathrm{~nm}\right)$ region and two in the visible $\left(625 \mathrm{~nm},{ }^{4} \mathrm{~A}_{2}^{\prime} \rightarrow{ }^{4} \mathrm{~A}_{2}^{\prime}(\mathrm{P}) ; 450-550 \mathrm{~nm},{ }^{4} \mathrm{~A}_{2}^{\prime} \rightarrow\right.$ $\left.{ }^{4} E^{\prime}(P)\right)$ region $[29,40]$. The absorption band at $625 \mathrm{~nm}$ has been used as a diagnostic transition for trigonal. bipyramidal spectra [41]. The optical transitions shown in Fig. 5 are consistent with the assignment of each $\mathrm{Co}^{2}+$ center adopting a trigonal bipyramidal structure. The observed molar extinction coefficients of 160 and 120 , respectively, are within the range reported for these transitions: $100-300$ for ${ }^{4} \mathrm{~A}_{2}^{\prime}$ and $100-600$ for ${ }^{4} \mathrm{E}^{\prime}$. While octahedral complexes also show bands in this same region $\left({ }^{4} \mathrm{~T}_{1 \mathrm{~g}}(\mathrm{~F}) \rightarrow{ }^{4} \mathrm{~T}_{2 \mathrm{~g}}\right.$ (F) $(950-1550 \mathrm{~nm})$ and ${ }^{4} \mathrm{~T}_{1 \mathrm{~g}}(\mathrm{~F}) \rightarrow{ }^{4} \mathrm{~T}_{1 \mathrm{~g}}(\mathrm{P})(450-650 \mathrm{~nm})$, the molar extinction coefficients of the ${ }^{4} \mathrm{~T}_{1 \mathrm{~g}}(\mathrm{~F}) \rightarrow{ }^{4} \mathrm{~T}_{2 \mathrm{~g}}(\mathrm{~F})$ transition typically range from 5 to 40 while those of the ${ }^{4} T_{1 g}(F) \rightarrow{ }^{4} T_{1 g}(P)$ transition range from 15 to 60 , well below those reported for $2[29,40]$. In comparison, the binuclear $\mathrm{Fe}^{2+}$ compound 5, appears featureless in the visible region owing to a strong tailing absorbance at $312 \mathrm{~nm}\left(\varepsilon_{\mathrm{M}}=\right.$ $30000)$ [9]. The chemical $\left(I_{2}\right)$ oxidations to 3 and 4 are clean with isosbestic points found at 660 and $356 \mathrm{~nm}$ for the conversion of $2 \rightarrow 3$ and 700 and $340 \mathrm{~nm}$ for the conversion of $3 \rightarrow 4$. The mixed valent $\left[\mathrm{Co}^{2+}, \mathrm{Co}^{3+}\right]$ complex 3, shows a peak at $305 \mathrm{~nm}\left(\varepsilon_{\mathrm{M}}=17400\right)$ and at $334 \mathrm{~nm}\left(\mathrm{sh}, \varepsilon_{\mathrm{M}}=14500\right)$, while the $\left[\mathrm{Co}^{3+}, \mathrm{Co}^{3+}\right]$ complex 4, shows a peak at $357 \mathrm{~nm}\left(\varepsilon_{M}=15000\right)$ (Fig. 5). Owing to the intense tailing absorbance from the phenoxy- $\mathrm{Co}^{3+}$ LMCT transition, no ligand field absorbances were identified for complexes 3 and 4 . The characteristic absorption spectrum of the mixed-valence complex suggests that a one-electron oxidation of 2 does not result in disproportionation but results in the formation of a discrete mixed valent species as such a reaction is expected to show absorptions due to $\left[\mathrm{Co}^{2+}\right.$ $\left.\mathrm{Co}^{2+}\right]$ and $\left[\mathrm{Co}^{3+} \mathrm{Co}^{3+}\right]$ species. Infrared spectroscopy on solid samples of 2 showed amide $v_{\text {amideco }}$ (1640 $\left.\mathrm{cm}^{-1}\right)$ and $v_{\text {amideNH }}\left(3450 \mathrm{~cm}^{-1}\right)$ stretching bands, both of which remain unchanged from their respective values observed in the $\mathrm{Li}^{+}$salt of the free ligand and in $5[8,9]$. Complexes 3 and 4 also show the same infrared features with the $v_{\text {amideco }}$ bands at 1656 and $1660 \mathrm{~cm}^{-1}$, respectively.

Solution magnetic moments of the Co complexes $\left[\mathrm{Co}^{2+}, \mathrm{Co}^{2+}\right](2)\left[\mathrm{Co}^{2+}, \mathrm{Co}^{3+}\right](3)$ and $\left[\mathrm{Co}^{3+}, \mathrm{Co}^{3+}\right](4)$ in DMSO were measured by Evans' method [20] at 293 K. Complex 2 gave a magnetic moment of $6.90 \mathrm{BM}$ per dimer, consistent with a high spin binuclear $\mathrm{Co}^{2+}$ $\left(S_{1}=S_{2}=3 / 2\right)$ complex [41]. Mononuclear high spin $\mathrm{Co}^{2+}$ complexes are generally found to have a magnetic moment between 3.98 and 5.40 BM [29], suggesting that the two $\mathrm{Co}^{2+}$ centers are interacting through the bridging phenoxide groups. This value is somewhat lower than the magnetic moments reported for a series of binuclear $\mathrm{Co}^{2+}$ complexes based on the $\mathrm{Bpmp}^{-}$ ligand system that gave solution magnetic moments per dimer of 8.2-9.6 BM [42]. However, many of these complexes are believed to be six-coordinate which are reported to have larger magnetic moments than five-coordinate complexes owing to greater contribution from orbital angular momentum in the ${ }^{4} \mathrm{~T}_{1 \mathrm{~g}}$ ground state in octahedral symmetry [43]. This interpretation is also supported by data for the mixed valent complex 3 that was found to have a magnetic moment of $4.78 \mathrm{BM}$, consistent with a dimeric species having a high spin five-coordinate $\mathrm{Co}^{2+}\left(\mu_{\mathrm{B}}=4.26-5.03\right)$ and a low spin $\mathrm{Co}^{3+}\left(S_{1}=3 / 2, S_{2}=0\right)$. The $\left[\mathrm{Co}^{3+}, \mathrm{Co}^{3+}\right]$ dimeric complex (4) gave a small magnetic moment (0.25 BM), in agreement with its expected diamagnetic behavior. The small moment could be attributed to less than $3 \%$ $\mathrm{Co}^{2+}$ in solution that resulted from incomplete oxidation of the reduced dimer, 2. The diamagnetic assignment of 4 is supported by its ${ }^{1} \mathrm{H}$ NMR spectrum that shows no significant paramagnetic shifts or broadening. A value of $\mu_{\mathrm{B}}=8.09$ (DMF, $298 \mathrm{~K}$ ) was recorded for the isostructural complex 5, which consists of two weakly (ferromagnetically) coupled high spin $\mathrm{Fe}^{2+}$ centers $\left(S_{1}=S_{2}=2, S_{\mathrm{T}}=4\right)$ [9].

Interpretation of the EPR spectra of the $\left[\mathrm{Co}^{2+}, \mathrm{Co}^{2+}\right]$, $\left[\mathrm{Co}^{2+}, \mathrm{Co}^{3+}\right]$, and $\left[\mathrm{Co}^{3+}, \mathrm{Co}^{3+}\right]$ complexes is consistent with the conclusions based on the magnetic susceptibility data. The presence of excited energy levels quite close to the ground state, which is independent of coordination geometry, induces fast relaxation of the three unpaired electrons leading to the type of broad spectra (500-4500 Gauss) shown in Fig. 6 for 2 even at $4 \mathrm{~K}[29,44]$. These data suggest that the two $\mathrm{Co}^{2+}$ centers are not strongly antiferromagnetically coupled. The EPR signal arising from 2 was found to be slightly broader ( 700 Gauss) than the signal arising from an equivalent $\mathrm{Co}^{2+}$ concentration of $\left[\mathrm{Co}^{2+}(\text { EDTA })\right]^{2-}$. This observation suggests the presence of additional 
interactions between the two cobalt atoms that affect spin-relaxation pathways leading to a broadening of the EPR resonance, consistent with 2 maintaining its binuclear structure in solution. The spectrum of complex 3 shows an identical signal to that obtained for 2 but with half the intensity as determined by spin integration (Fig. 6). This is expected for a mixed-valence complex having a high spin $\mathrm{Co}^{2+}$ atom and an EPR silent low spin $\mathrm{Co}^{3+}$ atom. No significant signal was observed for the fully oxidized $\mathrm{Co}^{3+}$ complex 4 as expected for a diamagnetic species. Spin integration indicated the presence of a small $(3 \%) \mathrm{Co}^{2+}$ impurity, consistent with the magnetic susceptibility data. These results are in contrast to EPR studies on 5 that reveal an integer spin feature at $g=16$ at $4 \mathrm{~K}$, consistent with a ferromagnetically coupled binuclear $\mathrm{Fe}^{2+}$ compound [9].

Cyclic voltammetry experiments were performed to assess the redox potentials linking the three core oxidation states. Measurements over the range of $+0.00 \mathrm{~V}$ (versus SCE) to $-1.4 \mathrm{~V}$ showed the same features for complexes 2, 3, and 4. Ligand centered redox processes occur outside this region and did not interfere with the examination of metal based processes. At concentrations of $2 \mathrm{mM}$ and scan rates of $100 \mathrm{mV} \mathrm{s}^{-1}$ and slower, a large oxidative adsorption peak is observed at $-570 \mathrm{mV}$ that gives rise to two reductive peaks at -1.22 and $-1.02 \mathrm{~V}$. However, at higher scan rates $\left(>100 \mathrm{mV} \mathrm{s}^{-1}\right.$ ), the adsorption phenomenon is minimized and two oxidative peaks coupled to the two reductive peaks can be observed at -570 and -340 $\mathrm{mV}$, respectively, suggesting the presence of two discrete redox couples at $E_{1 / 2}^{1}=-680 \mathrm{mV}$ and $E_{1 / 2}^{2}=$ $-890 \mathrm{mV}$. The nature of these irreversible redox processes $\left(\Delta E_{\mathrm{p}}^{1}=650 \mathrm{mV} ; \Delta E_{\mathrm{p}}^{2}=680 \mathrm{mV}\right)$ appear independent of either the nature of the electrode or the solvent system. Consecutive scans show the same voltammogram, with the absence of new species ruling out decomposition of the complexes during the experiment. The lack of 'reversible' electrochemical properties most likely reflects problems of the heterogeneous electron transfer process itself as well as the electronic redistri-

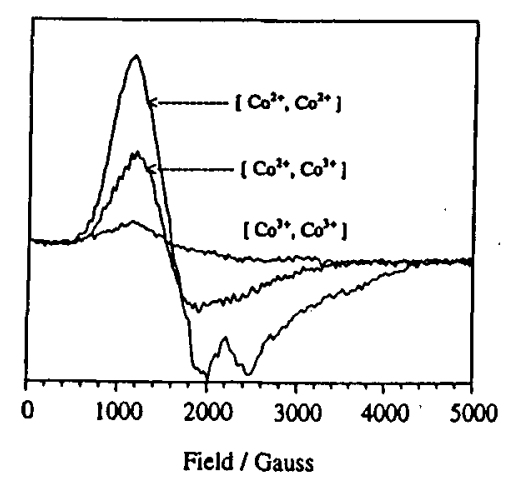

Fig. 6. EPR spectra of $1 \mathrm{mM}$ solutions of $\left[\mathrm{Co}^{2+}, \mathrm{Co}^{2+}\right](2),\left[\mathrm{Co}^{2+}\right.$, $\left.\mathrm{Co}^{3+}\right](3)$, and $\left[\mathrm{Co}^{3+}, \mathrm{Co}^{3+}\right](4)$, in DMF at $4 \mathrm{~K}$. bution and structural reorganization that is expected to occur upon oxidation of $\mathrm{Co}^{2+}$ to $\mathrm{Co}^{3+}$. This behavior is in contrast to the electrochemical properties reported for 5 which exhibited one quasi-reversible $\left(E_{1 / 2}^{1}=-\right.$ $\left.500 \mathrm{mV} ; \Delta E_{\mathrm{p}}^{1}=240 \mathrm{mV}\right)$ and one reversible $\left(E_{1 / 2}^{2}=-\right.$ $250 \mathrm{mV} ; \Delta E_{\mathrm{p}}^{2}=70 \mathrm{mV}$ ) redox process [9]. The large $\Delta E_{\mathrm{p}}$ of these peaks suggests a structural change. The comproportionation constant, $K_{\text {com }}$, describing the stability of the mixed-valence species, was calculated to be $K_{\text {com }}=1.7 \times 10^{4}$ suggesting that the mixed-valence form is only moderately stable. Electrochemical studies on 5 indicated that pronounced scan rate dependence of the $\Delta E_{\mathrm{p}}^{1}$ values and the scan rate independent $\Delta E_{\mathrm{p}}^{2}$ values is consistent with an $\mathrm{EC}$ mechanism caused by a rearrangement of the core structure upon the $1 \mathrm{e}^{-}$ oxidation of the diferrous core. However, while the overall electrochemical behavior of 2 parallels that observed for 5, the extreme irreversibility of the cobalt system precludes any direct comparison and meaningful analysis of the oxidation potentials.

\subsection{Catalysis}

The ability of the $\left[\mathrm{Co}^{2+}, \mathrm{Co}^{2+}\right](2),\left[\mathrm{Co}^{2+}, \mathrm{Co}^{3+}\right](3)$, and $\left[\mathrm{Co}^{3+}, \mathrm{Co}^{3+}\right](4)$, complexes to catalyze oxygen atom transfer reactions from OIPh to a variety of olefinic substrates is summarized in Table 6. Overall, the turnover numbers and efficiencies show that 2-4 are good oxo atom transfer catalysts for these representative olefins. In all cases, no oxidation products were generated when OIPh was omitted; quantitative $\mathrm{PhI}$ is produced as the final product of OIPh. Parallel control reactions in which the catalyst was omitted showed only negligible product formation, indicating the stability of the substrates under these reaction conditions.

Immediately evident is the observation that $\mathrm{CO}^{2+}$, $\mathrm{Co}^{2+}$ ] compound, 2, catalyzed OIPh oxidation of cyclohexene produces predominantly $(85 \%)$ cyclohexene epoxide with only minor quantities of products arising from the oxidation of the allylic position. This reaction (Eq. (1)), which occurs with high efficiency, produces a

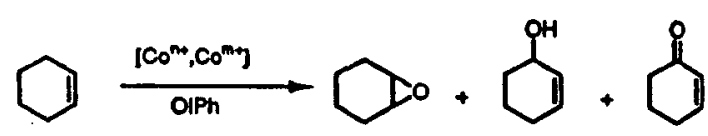

product distribution that is significantly different from that reported for the isostructural $\left[\mathrm{Fe}^{2+}, \mathrm{Fe}^{2+}\right]$ complex, 5, which under identical reaction conditions gave two dominant products $(75 \%)$ generated from oxidation of the allylic position. Since $\mathbf{2}$ and $\mathbf{5}$ are isostructural, the different product distributions must arise from differences in the d-electron count and how they influence the nature of the reactive intermediate(s) formed during catalysis. In addition, neither $\mathrm{Co}^{2+}\left(\right.$ salen) nor $\mathrm{CCo}^{3+}$ (salen) $]^{+}$were found to be active as oxygen atom transfer catalysts, indicating the requirement for the 


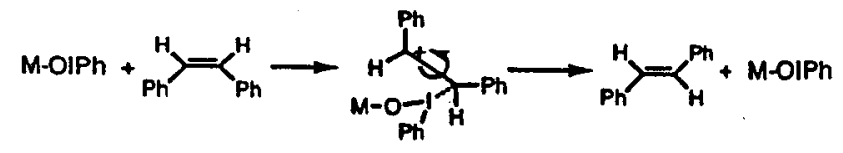

Scheme 3.

electronic environment produced by the $\mathrm{H}_{2} \mathrm{Hbab}^{2-}$ ligand system. As reported in the literature [6] and reproduced here, simple inorganic salts such as $\mathrm{Co}^{2+}$ $\left(\mathrm{NO}_{3}\right)_{2}$ showed marginal activity, clearly below that exhibited by $2-4$. Furthermore, when tert-butyl hydrogen peroxide is used as the oxidant, only tert-butylperoxy-2-cyclohexene, resulting from peroxide homolysis, is observed, indicating the inability of 2 to induce heterolytic cleavage of the peroxy $\mathrm{O}-\mathrm{O}$ bond. Also interesting is the lack of any apparent influence of the binuclear core oxidation state on the distribution of epoxidation versus allylic oxidation, suggesting minimal interaction between the metal center and oxygen atom in the reactive intermediate. This observation contrasts the dramatic influence played by metal centered electron density reported for the epoxidation of cyclohexene by electronegative versus electropositive metal porphyrin systems where high valent metal-oxo reactive intermediates act as the oxidation catalysts [45].

Table 6 also shows that while both mixed-valence complexes, $\left[\mathrm{Co}^{2+}, \mathrm{Co}^{3+}\right](3)$, and $\left[\mathrm{Fe}^{2+}, \mathrm{Fe}^{3+}\right](6)$, are capable of catalyzing the oxidation of cyclohexene giving product distribution approximating those of their respective reduced counterparts, significant differences are observed for the fully oxidized members of this series. This work and previous studies show that oxygen atom transfer catalysis occurs only in the presence of a ferrous center; the oxidized $\left[\mathrm{Fe}^{3+}, \mathrm{Fe}^{3+}\right]$ complex, 7 , is inactive as an oxidation catalyst [8]. However, the $\left[\mathrm{Co}^{3+}, \mathrm{Co}^{3+}\right]$ complex, 4 , is as effective a catalyst as are 2 and 3 , indicating the complete insensitivity of the reaction chemistry to the oxidation state of the cobalt center.

Reaction of 2-4 with cis-stilbene gives predominantly retention of stereochemistry with only trace amounts of the trans-oxide observed in each case (Eq. (2)). Although the observation of isomerization has

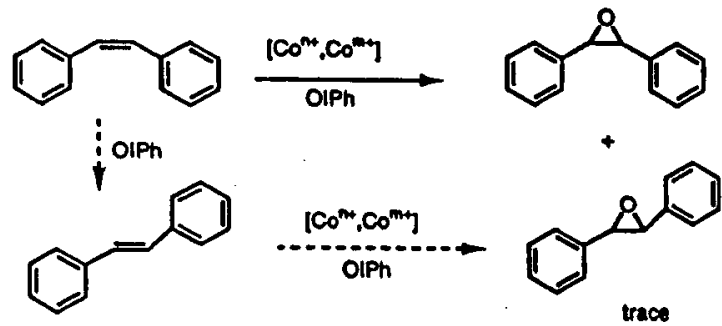

been used in previous mechanistic studies as evidence for a carbocation or radical intermediate, recent studies have shown that the trans-oxide product may arise from oxidation of trans-olefin generated by a metal
$\mathrm{OIPh}$ catalyzed isomerization pathway involving the initial electrophilic addition of OIPh to the cis-olefin (Scheme 3) [6].The resulting carbocation is capable of collapsing to the thermodynamically more stable transolefin. Operation of this pathway is supported by identification of quantities of unreacted trans-stilbene in reactions initiated with pure cis-stilbene (Table 6). No such isomerization products are observed in reactions with trans-stilbene. These data suggest that oxo atom transfer occurs through a process where rotation about the carbon-carbon bond of the olefin is not significant [46], arguing against any long-lived organic intermediate. Interestingly, while 2 and 4 showed no real preference for either the cis-or trans-olefin, 5 was unreactive towards cis-stilbene but demonstrated the ability to catalyze the oxidation of trans-stilbene to its corresponding epoxide.

Catalytic oxidations of norbornene by $2-4$ give only the exo-epoxide, consistent with electrophilic or electrocyclic reactions on norbornene (Eq. (3)) [45]. Our in-

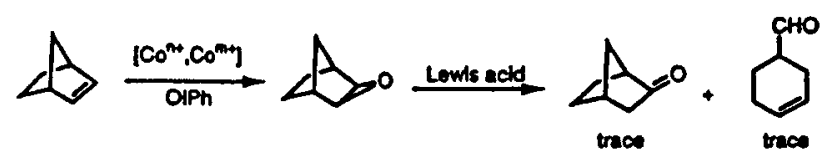

ability to detect any endo isomer allows us to state only a lower limit for the exo/endo ratio as 110:1, although the true ratio is in all probability much greater than this value. The mechanistic implications for the synthesis of the endo epoxide arise from the well documented chemistry of norbornene, 2-norbornyl carbocation and 2norbornyl radical towards a spectrum of reagents. Previous studies have established that peracid epoxidation, electrocyclic additions, the formation of norbornene-metal complexes and the addition of electrophiles or radicals occur exclusively on the exo side. The catalysis data for 2-4 are therefore consistent with direct electrophilic, radical or molecular attack on the substrate. The observation of low levels of norcamphor and cyclohexene-4-carboxaldehyde is consistent with this conclusion as these products, found in MCPBA oxidations of norbornene, are generated by Lewis acid catalyzed rearrangement of the exo-epoxide [47].

The lack of any observable endo isomer also prevented an examination of the effect of electron density at the $\mathrm{Co}^{n+}$ centers (oxidation states) on the exo/endo ratio as a test for a change in mechanism from electrophilic or electrocyclic pathway to an electron transfer mechanism as a function of the core oxidation states [45]. Studies examining the influence of electron density on metalloporphyrin catalyzed OIPh oxidation of norbornene suggest that electronegative porphyrin catalysts follow a limiting electron transfer pathway while electropositive porphyrin catalysts follow electrophilic addition mechanisms. Experiments designed to define this effect for $2-4$ require further efforts. 
Oxidation of sulfides to their corresponding sulfoxides and sulfones requires a two-electron oxidizing agent (Eq. (4)). Consequently, they have proven useful

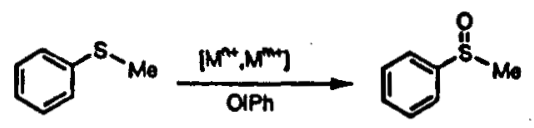

in studies examining the metal catalyzed oxidation of alkanes and olefins by alkyl hydroperoxides [48]. When such substrates are mixed with reagents such as $\mathrm{Me}_{2} \mathrm{~S}$ or $p$-methoxythioanisole, the latter are proposed to react readily with high valent metal-oxo intermediates generated by the heterolytic cleavage of alkyl hydroperoxides in both non-heme and heme-catalyzed systems thereby affecting olefin or alkane oxidation processes [48]. The presence of sulfides is not expected to alter the product distribution arising from intermediates generated from peroxide homolysis. Table 6 shows that 2 is unable to perform the direct oxidation of $\mathrm{PhSMe}$ in the presence of $\mathrm{OIPh}$ while its isostructural iron analog, 5, under identical conditions, produces both the corresponding sulfoxide and sulfone [8].

These data, in total, clearly indicate that the isostructural complexes 2 and 5 , which differ only by d-electron count, follow distinct mechanistic pathways. This conclusion makes the implications of this comparative reactivity study quite interesting. Previous studies showed that methanolic solutions of the binuclear $\mathrm{Fe}^{2+}$ compound, $\mathbf{5}$, catalyze the heterolytic decomposition of phenylperacetic acid (to yield phenylacetate and formaldehyde from solvent) while its oxidized $\left[\mathrm{Fe}^{3+}\right.$, $\left.\mathrm{Fe}^{3+}\right]$ form, 7 , only catalyzes homolysis of the peracyl $\mathrm{O}-\mathrm{O}$ bond [8]. Furthermore, while 5 demonstrated the ability to catalyze the OIPh allylic oxidation of cyclohexene, epoxidize olefins, and oxidize sulfides to sulfoxides and sulfones, 7 was completely inactive as an oxidation catalyst despite its ready ability to form adducts with a variety of small molecules such as catechols and phenols [8]. In the absence of substrates, 5 reacts under anaerobic conditions with stoichiometric $\mathrm{OIPh}$ to quantitatively produce a $\mu$-oxo $\mathrm{Fe}^{3+}$ dimer complex whose $\mathrm{Fe}-\mathrm{O}-\mathrm{Fe}$ asymmetric stretch was identified by ${ }^{18} \mathrm{O}$ isotopic labeling studies [8]. These data were explained by a mechanism (Scheme 4 ) involving a reactive intermediate which, in the limiting cases, can be viewed as arising from the interaction of 5 with $\mathrm{OIPh}$ to form either (i) an OIPh adduct by coordination of the $\mathrm{I}^{3+}$ center thereby increasing the electrophilicity of the oxygen atom by polarization effects, or, (ii) $\mathrm{a}\left[\mathrm{Fe}^{4+}=\mathrm{O}\right]$ species generated by the formal transfer of the oxygen atom from OIPh to a ferrous center. While the direct unambiguous characterization of a non-heme iron ferryl species has not as yet been reported, the $\left[\mathrm{Fe}^{4+}=0\right]$ unit has been invoked on the basis of reactivity studies [7].
The catalytic chemistry of the isostructural $\mathrm{Co}^{2+}$ complex 2 assumes significance in differentiating between an adduct versus metal-oxo pathway. Examination of the results derived from molecular orbital theory for five- and six-coordinate transition metal complexes shows that a formal $\left[\mathrm{M}^{n+}=\mathrm{O}\right]$ functionality can only occur for those metal centers having a $\mathrm{d}^{4}$ or less electron configuration [3,4]. It is energetically highly unlikely that $\mathrm{Co}^{2+}$ will react with OlPh and form a high valent metal-oxo species $\left(d^{5}\right)$ as the extra electron beyond the $\mathrm{d}^{4}$ configuration would reside in a metal oxygen antibonding orbital, thereby reducing the bond order below that required for this type of species [4]. A similar argument applies to any system in which the $d$ orbitals are filled. Thus, low-spin six-coordinate $d^{6}$ complexes $\left(\mathrm{Co}^{3+}\right)$ are also not expected to easily reach the high oxidation states needed to have empty $d$ orbitals necessary for the preparation of a terminal metal-oxo complex. These MO constraints do not, however, preclude the formation of a high-valent ironoxo species. Nonetheless, the chemistry exhibited by the $\left[\mathrm{Co}^{2+}, \mathrm{Co}^{2+}\right],\left[\mathrm{Co}^{2+}, \mathrm{Co}^{3+}\right]$, and $\left[\mathrm{Co}^{3+}, \mathrm{Co}^{3+}\right]$ core oxidation states is consistent with an enhancement of the electrophilicity of the oxygen atom of OIPh.

The chemical reactivity observed for the binuclear Co complexes 2-4 is consistent with that reported by Valentine and co-workers [ 6 ] in which non-redox active $\left(\mathrm{Zn}_{2}^{2+} \mathrm{Pedab}, \mathrm{Al}^{3+}(\mathrm{OTf})_{3}\right)$ as well as redox active $\left(\mathrm{Mn}_{2}^{2+}(\right.$ Pedab $), \mathrm{Cu}_{2}^{2+}($ Pedab $), \mathrm{Co}_{2}^{2+}($ Pedab $)$, and $\left.\left[\mathrm{Fe}^{3+}(\mathrm{Bpb})(\mathrm{OTf})_{2}\right]^{-}\right)$complexes catalyzed oxygen atom transfer from OIPh to a variety of olefins. This work, based on earlier studies examining the linkage between metal catalyzed OIPh oxidations and electrophilic addition of $\mathrm{I}^{3+}$ to olefinic double bonds [49], concluded that $\mathrm{I}^{3+}$ and not the oxygen atom or the metal center is the reactive electrophilic site responsible for catalysis. Initial attack of a metal OIPh complex with an olefinic substrate is thought to result in an intermediate similar to 8 (Scheme 5) which rearranges to give 9 before decomposing under reaction conditions to yield the epoxide product. In all cases, similar product distributions were obtained for both redox inactive and redox active metal complexes; the oxidation of cyclohexene yielded primarily the epoxide with only minor quantities of allylic oxidation products observed. The Valentine mechanism describes a pathway for transition metal catalyzed oxygen atom transfer that does not involve a change in metal oxidation state, consistent

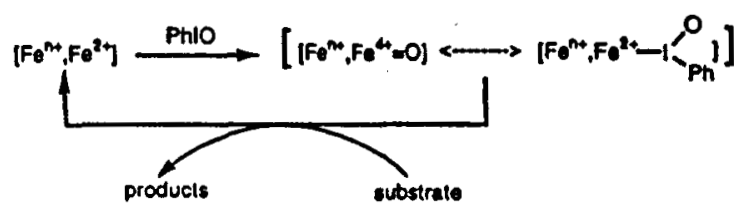

Scheme 4. 

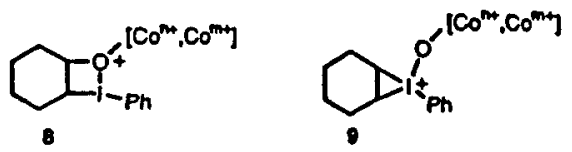

Scheme 5 .

with the chemistry exhibited by $2-4$. Therefore, these cobalt based catalysts do not appear to fit the classification of either a primary or secondary oxo transfer catalyst, all of which require a change in the metal centers oxidation state [3]. The observation that all core oxidation states found in 2-4 can function as oxidation catalysis, the dominance of epoxide products over allylic oxidation products, and the inability of 2-4 to catalyze the oxidation of sulfides to sulfoxides suggests that complexes 2-4 act as Lewis acid catalysts for olefin epoxidation when OIPh is used as the oxygen atom donor. Other potential intermediates, such as reactive $\mu$-oxo bridged species formed by the one-electron oxidation of each metal center, are believed to be unlikely owing to the approximate catalytic equivalence of the $\left[\mathrm{Co}^{2+}, \mathrm{Co}^{2+}\right]$ and $\left[\mathrm{Co}^{3+}, \mathrm{Co}^{3+}\right]$ complexes. Although metal-oxo bonding considerations might predict the possibility of such reactive $\mu$-oxo species, they are expected to access significantly different core oxidation states of the cobalt centers which should differentially influence the catalytic properties of 2 and 4 .

$\left[\mathrm{Co}^{2+}(\mathrm{acac})_{3}\right]^{-}$and $\mathrm{Co}^{2+}$ porphyrins [50] are known to act as autooxidation catalysts in the presence of oxygen. These reactions go through a free radical chain process with an initial induction period. All reactions reported herein were performed under anaerobic conditions; no induction period was observed in the OIPh epoxidation of cyclohexene with 2-4. However, when tert-butyl hydrogen peroxide is used as the oxidant, $\mathbf{2}$ is unable to oxidize cyclohexene to produce either the epoxide or allylic oxidation products but instead yields 1-(tert-butylperoxy)-2-cyclohexene, consistent with a free radical pathway. Control experiments demonstrated that cyclohexene oxide is stable under the reaction and subsequent workup conditions. Thus, 2 can follow one of two pathways depending on the nature of the oxidant. The occurrence of a dual mechanism is similar to a report by Kochi and co-workers who examined the ability of a proposed mononuclear $\mathrm{Co}^{2+}$ complex of a related ligand system, $\mathrm{Cl}_{4} \mathrm{Me}_{4}$ salam, to catalyze the OIPh and tert-butyl hydrogen peroxide oxidations of olefins [51]. While only the chemistry of the $\mathrm{Co}^{2}+$ species was reported in detail, both a radical $\left(\mathrm{Co}^{2+}\right.$ induced homolytic cleavage of the peroxy $\mathrm{O}-\mathrm{O}$ bond) and non-radical (putative $\left[\mathrm{Co}^{4+}=\mathrm{O}\right]$ intermediate generated from OIPh) pathways were postulated. Differences in these systems is apparent as Kochi reports the ability of $\mathrm{Co}^{2+}\left(\mathrm{Cl}_{4} \mathrm{Me}_{4}\right.$ salam $)$ to catalyze the $\mathrm{OIPh}$ oxidation of cyclohexane to yield cyclohexanol
$(1 \%)$ and cyclohexanone $(20 \%)$, a reaction that is not catalyzed by $2-4$. A more direct comparison of these systems is precluded by the present lack of characterization of $\mathrm{Co}^{2+}\left(\mathrm{Cl}_{4} \mathrm{Me}_{4}\right.$ salam $)$.

The significantly different product distributions observed under identical conditions for the binuclear cobalt and iron complexes argues against a common reactive intermediate operating in both catalytic cycles. The inability of the diferric complex, 7 , to act as a catalyst, even though it has the ability to form adducts, the predominance of allylic oxidation products for the diferrous and mixed-valence catalyzed reactions, and the oxidation of sulfides to sulfoxides suggests that the iron based systems are not operating as simple Lewis acid catalysts (Scheme 4). While the iron based systems demonstrate reactivity properties consistent with a variety of non-heme iron monooxygenases [7], the current absence of any direct spectroscopic evidence of a metaloxo intermediate precludes any unambiguous conclusions concerning the nature of the reactive species [7].

\section{Conclusions}

We have reported a family of binuclear $\left[\mathrm{Co}^{2+}, \mathrm{Co}^{2+}\right]$, $\left[\mathrm{Co}^{2+}, \mathrm{Co}^{3+}\right]$, and $\left[\mathrm{Co}^{3+}, \mathrm{Co}^{3+}\right]$ complexes that are each capable of catalyzing the OIPh epoxidation of olefins. X-ray crystallographic and spectroscopic characterization of the $\left[\mathrm{Co}^{2+}, \mathrm{Co}^{2+}\right]$ compound, 2, shows that it is isostructural with $\mathrm{Fe}_{2}\left(\mathrm{H}_{2} \mathrm{Hbab}\right)_{2}(\mathrm{~N}-\mathrm{MeIm})_{2}$ (6), which is also an active oxo-transfer catalyst. Owing to (i) the ability of the high spin $\mathrm{d}^{7} \mathrm{Co}^{2+}$ and low spin $\mathrm{d}^{6} \mathrm{Co}^{3+}$ complexes to both catalyze the OIPh oxidation of olefins yielding identical product distributions (primarily epoxides); (ii) the inability of 2 to catalyze the two-electron oxidation of sulfides to sulfoxides; (iii) the inability of $\mathrm{Co}^{2+}$ centers to readily form a $\left[\mathrm{Co}^{4+}\right.$ $=0$ ] functionality; (iv) the dramatic differences in product distributions observed for isostructural 2 versus 6 (epoxidation versus allylic oxidation and sulfide oxidation, respectively); and (v) the inability of the fully oxidized $\left[\mathrm{Fe}^{3+}, \mathrm{Fe}^{3+}\right]$ complex to catalyze any oxygen atom transfer process, we propose that different reactive intermediates are formed by these two sets of metal complexes. These data clearly show the effect of d-electron count on the mechanism of catalytic oxidation of olefins by non-heme metal complexes and suggest that two distinct mechanistic pathways are operational. The characteristics of the cobalt catalyzed reactions are consistent with the metal center forming an adduct with $\mathrm{OIPh}$ and acting as a Lewis acid catalyst in which it plays a redox inactive role while the iron based catalytic systems clearly demonstrate an absolute requirement for the presence of at least one ferrous center. These insights allow us to argue against the role of a simple OIPh adduct as the reactive species in the case of the 
iron systems as was proposed in part to explain their catalytic properties. While the data are consistent with the reactivity properties of a $\left[\mathrm{Fe}^{4+}=\mathrm{O}\right]$ containing species, direct spectroscopic characterization necessary to verify its existence is currently unavailable. Studies designed to directly (spectroscopically) and indirectly (mechanistically) probe the nature of the reactive intermediates for both the cobalt and iron systems are currently underway.

\section{Supplementary material}

Tables of positional and thermal parameters, interatomic distances, intramolecular bond angles, crystal data and solution refinement details for $\operatorname{Co}(N$ $\mathrm{MeIm})_{2}(\mathrm{Cl})_{2}$ (1), and $\mathrm{Co}_{2}{ }^{2+}\left(\mathrm{H}_{2} \mathrm{Hbab}\right)_{2}(\mathrm{~N}-\mathrm{MeIm})_{2}$ (2) are available from the authors on request.

\section{Acknowledgements}

We thank donors of the Petroleum Research Fund and the Department of Energy (ER 14279) for support of this work. We appreciate the help of Dr D. Koulougliotis for his efforts during the EPR studies and Gayle Schulte for aid in the X-ray crystallographic characterizations.

\section{References}

[1] (a) P.R. Ortiz de Montellano (Ed.), Cytochrome P-450: Reactions, Mechanism and Biochemistry, Plenum, New York, 1986. (b) M.J. Gunter, P. Turner, Coord. Chem. Rev. 108 (1991) 115. (c) B. Meunier, Chem. Rev. 92 (1992) 1411. (d) J.P. Collman, X. Zhang, V.J. Lee, E.S. Uffelman, J.I. Brauman, Science 261 (1993) 1404.

[2] Y. Tatsuno, A. Sekiya, K. Tani, T. Saito, Chem. Lett. (1986) 889.

[3] R.H. Holm, Chem. Rev. 87 (1987) 1401

[4] J.M. Mayer, Comments Inorg. Chem. 4 (1988) 125.

[5] (a) W. Nam, J.S. Valentine, J. Am. Chem. Soc. 112 (1990) 4977. (b) Y. Yang, F. Diederich, J.S. Valentine, J. Am. Chem. Soc. 112 (1990) 7826.

[6] (a) Y. Yang, F. Diederich, J.S. Valentine, J. Am. Chem. Soc. 113 (1991) 7195. (b) W. Nam, J.S. Valentine, J. Am. Chem. Soc. 115 (1993) 1772.

[7] (a) J.P. Caradonna, A. Stassinopoulos, Advances in Inorganic Biochemistry, L.G. Marzilli, G.L. Eichhorn (Eds.), Elsevier, New York, 1993, Ch. 7, 245. (b) A.L. Feig, S.J. Lippard, Chem. Rev. 94 (1994) 759. (c) L. Que Jr., A.E. True, in: S.J. Lippard (Ed.), Prog. Inorg. Chem., vol. 38 Wiley, New York, 1990, p. 97.

[8] A. Stassinopoulos, J.P. Caradonna, J. Am. Chem. Soc. 112 (1990) 7071.

[9] A. Stassinopoulos, G. Schulte, G.C. Papaefthymiou, J.P Caradonna, J. Am. Chem. Soc. 113 (1991) 8686.

[10] F.C. Anson, J.A. Christie, T.J. Collins, R.J. Coots, T.T. Furutani, S.L. Gipson, T.E. Kraft, B.D. Santarsiero, G.H. Spies, J. Am. Chem. Soc. 106 (1984) 4460.
[11] (a) K.H. Pausacker, J. Chem. Soc. (1953) 107. (b) H. Saltzman, J.G. Sharefkin, M.S. Newman, N. Gill, Org. Synth. 43 (1962) 60.

[12] R.H. Bailes, M. Calvin, J. Am. Chem. Soc. 69 (1947) 1886.

[13] T. Tsumaki, Bull. Chem. Soc. Jpn. 69 (1947) 1886.

[14] (a) N.S. Gill, R.S. Nyholm, G.A. Barclay, T.I. Christie, P.J. Pauling, J. Inorg. Nucl. Chem. 18 (1961) 88. (b) W.L. Darby, L.M. Vallarino, Inorg. Chim. Acta 48 (1981) 215.

[15] Structure Solution Methods: J.C. Calbrese, PHASE-Patterson Heavy Atom Solution Extractor, University of WisconsinMadison, Ph.D. Thesis (1972); C.J. Gilmore, MITHRIL, an integrated direct methods computer program, J. Appl. Crystallogr. 17 (1984) 42; P.T. Beurkens, DIRDIF-Direct Methods for Difference Structures, an automated procedure for phase extension and refinement of difference structure factors, Technical Report 1984/1, Crystallographic Laboratory, Toernooiveld, 6525 ED Nijmegen, Netherlands; G.M. Sheldrick, sHeLXs86, Program for Crystal Structure Determination, 1986, University of Cambridge.

[16] D.T. Cromer, J.T. Waber, International Tables for X-ray Crystallography, vol. IV, Kynoch Press, Birmingham, UK, Table $2.2 \mathrm{~A}, 1974$.

[17] J.A. Ibers, W.C. Hamilton, Acta Crystallogr. 17 (1964) 781.

[18] D.T. Cromer, International Tables for X-ray Crystallography, vol. IV, Kynoch Press, Birmingham, UK, Table 2.3.1, 1974.

[19] TEXSAN, Single Crystal Structure Analysis Software, Version 5.0, 1989, Molecular Structure Corporation, The Woodlands, TX, 77381.

[20] (a) D.H. Live, S.I. Chan, Anal. Chem. 42 (1970) 791. (b) M. Wayer, U. Gerger, V. Gutmann, Monatsh. Chem. 108 (1977) 489.

[21] R.R. Gagne, C.A. Koval, G.C. Lisensky, Inorg. Chem. 19 (1980) 2855.

[22] W. Beck, G. Brudvig, J. Magn. Reson. (1991) 90.

[23] (a) F. Reitzenstein, Liebigs Ann. 282 (1894) 273. (b) A Hantzsch, Anorg. Chem. 159 (1927) 273.

[24] D. Buckingham, C.R. Clark, in: G. Wilkinson, R.D. Gillard, J.A. McCleverty (Eds.), Comprehensive Coordination Chemistry, Ch. 47, Pergamon, Oxford, 1987, pp. 635-900.

[25] (a) L.I. Katzin, J. Chem. Phys. 35 (1961) 467. (b) W. Libus, K. Chachulska, M. Mecik, Inorg. Chem. 19 (1980) 2259. (c) K. Sawada, K. Miura, T. Suzuki, Bull. Chem. Soc. Jpn. 55 (1982) 780. (d) K. Kojima, M. Saida, M. Donoue, J. Matsuda, Bull. Chem. Soc. Jpn. 56 (1983) 684.

[26] (a) A.B.P. Lever, S.M. Nelson, J. Chem. Soc. A (1966) 859. (b) A.B.P. Lever, Inorganic Electronic Spectroscopy, Ch. 6, Elsevier, Oxford, 1984, p. 376

[27] (a) F.A. Cotton, D.M.L. Goodgame, M. Goodgame, J. Am. Chem. Soc. 83 (1961) 1777. (b) F.A. Cotton, D.M.L. Goodgame, M. Goodgame, J. Am. Chem. Soc. 83 (1961) 4690. (c) J. Ferguson, J. Chem. Phys. 39 (1963) 116.

[28] (a) B.N. Figgis, R.S. Nyholm, J. Chem. Soc. (1954) 12. (b) B.N. Figgis, R.S. Nyholm, J. Chem. Soc. (1959) 338.

[29] L. Banci, C. Bencini, D. Gatteschi, C. Zanchini, Struct. Bonding 52 (1982) 37.

[30] M. Laing, G. Carr, Acta Crystallogr., Sect. B 31 (1975) 2683.

[31] L.J. Admiraal, G. Gafner, J. Chem. Soc., Chem. Commun. (1968) 1221.

[32] J.R. Allan, C.L. Jones, L. Sawyer, J. Inorg. Nucl. Chem. 43 (1981) 2707

[33] M.M. Kadooka, L.G. Warner, K. Seff, Inorg. Chem. 15 (1976) 812.

[34] M.G. Ehrlich, F.R. Fronczek, S.F. Watkins, G.R. Newkome, D.C. Hager, Acta Crystallogr., Sect. C 40 (1984) 78.

[35] J. Burgess, in: G. Wilkinson, R.D. Gillard, J.A. McCleverty (Eds.), Comprehensive Coordination Chemistry, Ch. 15.1, Pergamon, Oxford, 1987, p. 295.

[36] M. Suzuki, I. Ueda, H. Kanatomi, I. Murase, Chem. Lett. Jpn. (1983) 185. 
[37] V.D. Campbell, E.J. Parsons, W.T. Pennington, Inorg. Chem. 32 (1993) 1773.

[38] (a) T.P.E. Auf der Heyde, H.-B. Burgi, Inorg. Chem. 28 (1989) 3960. (b) T.P.E. Auf der Heyde, H.-B. Burgi, Inorg. Chem. 28 (1989) 3970. (c) T.P.E Auf der Heyde, H.-B. Burgi, Inorg. Chem. 28 (1989) 3982.

[39] S. Brückner, M. Calligaris, G. Nardin, L. Randaccio, Acta Crystallogr., Sect. B 25 (1969) 1671.

[40] L. Sacconi, M Ciampolini, F. Maggio, F.P. Cavasino, Inorg. Chem. (1962) 3247.

[41] M. Ciampolini, Struct. Bonding 6 (1969) 52.

[42] M. Suzuki, H. Kanatomi, I. Murase, Bull. Chem. Soc. Jpn. 57 (1984) 36.

[43] P.W. Ball, A.B. Blake, J. Chem. Soc., Dalton Trans. (1974) 852.

[44] (a) J.R. Pilbrow, Transition Ion Electron Paramagnetic Resonance, Clarendon, Oxford, 1990, Ch. 3, p. 144. (b) A. Abragam, B. Bleaney, Electron Paramagnetic Resonance of Transition Ions, Clarendon, Oxford, 1970.

[45] (a) T.G. Traylor, A.R. Miksztal, J. Am. Chem. Soc. 111 (1989)
7443. (b) T.G. Traylor, T. Nakano, B.E. Dunlap, P. Traylor, D. Dolphin, J. Am. Chem. Soc. 108 (1986) 2782.

[46] (a) E.G. Samsel, K. Srinivasan, J.K. Kochi, J. Am. Chem. Soc. 107 (1985) 7606. (b) J.T. Groves, W.J. Kruper Jr., R.C. Haushalter, J. Am. Chem. Soc. 102 (1980) 6375. (c) C.C. Franklin, R.B. Van-Atta, A.F. Tai, J.A. Valentine, J. Am. Chem. Soc. 106 (1984) 814.

[47] B. Rickborn, R.M. Gerkin, J. Am. Chem. Soc. 93 (1971) 1693.

[48] (a) R. Labeque, L. Marnett, J. Am. Chem. Soc. 111 (1989) 6621. (b) R.A. Leising, J. Kim, M.A. Perez, L. Que Jr., J. Am. Chem. Soc. 115 (1993) 9524.

[49] R.M. Moriarty, R. Penmasta, I. Prakash, Tetrahedron Lett. 26 (1985) 4699.

[50] (a) R.A. Budnick, J.K. Kochi, J. Org. Chem. 41 (1976) 1384. (b) Y. Ohkatsu, T. Tsuruta, Bull. Chem. Soc. Jpn. 51 (1978) 188. (c) D.R. Paulson, R. Ullman, R.B.J. Sloane, J. Chem. Soc., Chem. Commun. (1974) 186.

[51] J.D. Koola, J.K. Kochi, J. Org. Chem. 52 (1987) 4545. 


\title{
$\mathrm{Fe}^{2+}$-Catalyzed Heterolytic RO-OH Bond Cleavage and Substrate Oxidation: A Functional Synthetic Non-Heme Iron Monooxygenase System
}

\author{
Trina L. Foster and John P. Caradonna* \\ Department of Chemistry, Boston University, Boston, Massachusetts 02215
}

Received September 20, 2002; E-mail: caradonn@bu.edu

Nature has evolved a variety of strategies to utilize $\mathrm{O}_{2}$ for the controlled oxidation of organic molecules. ${ }^{1.2}$ The formal incorporation of an oxygen atom into unactivated $\mathrm{C}-\mathrm{H}$ bonds typically requires the use of transition metal centers in either the reduction of dioxygen to peroxide and/or in the formation of the reactive intermediate responsible for the oxidation reaction. ${ }^{1,3,4}$ Two fundamental mechanistic features observed in both mono- and binuclear non-heme iron-dependent monooxygenase pathways are (i) the heterolytic $\mathrm{O}-\mathrm{O}$ bond cleavage of an iron coordinated peroxide ligand and (ii) the subsequent tightly coupled transfer of one oxygen atom to substrate for each equivalent of dioxygen/peroxide consumed. ${ }^{35}$ Despite significant advances in our understanding of the structural, spectroscopic, and mechanistic issues of iron-based enzymatic alkane oxidation processes, the development of synthetic analogue systems that parallel key steps in the biological oxidation of hydrocarbons is still a major challenge. ${ }^{6}$ Although synthetic ferric mono- and binuclear model systems are reported to hydroxylate organic substrates in the presence of dioxygen or peroxides, studies implicate the significant involvement of oxygen-based free radical chemistry initiated by the homolytic cleavage of the peroxy $\mathrm{O}-\mathrm{O}$ bond. We have previously reported the ability of a synthetic binuclear ferrous compound, $\left[\mathrm{Fe}_{2}{ }^{2+}\left(\mathrm{H}_{2} \mathrm{Hbamb}\right)_{2}(\mathrm{~N} \text {-Melm })_{2}\right], 1^{7}$ (Figure 1), to catalyze the hydroxylation of alkanes, arenes, and sulfides in the presence of oxygen atom donor (OAD) molecules. ${ }^{8}$ Herein, we report (i) the ability of 1 to induce heterolytic cleavage of the alkyl hydroperoxide 2-methyl-1-phenylprop-2-yl hydroperoxide (MPPH) and (ii) the ability of 1 to efficiently catalyze the oxidation of phenyl methyl sulfide and cyclohexane using MPPH as the source of oxygen atom.

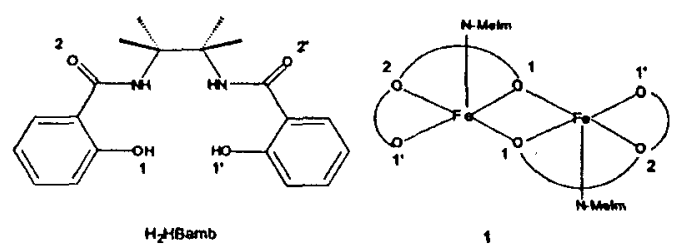

Flgure 1. Structures of ligand and iron complexes.

The use of MPPH as a mechanistic probe to distinguish homolytic versus heterolytic cleavage of alkyl hydroperoxide $0-0$ bonds is well established. ${ }^{6}$ The rapid $\beta$-scission process $\left(k_{\beta}=2 \times\right.$ $10^{8} \mathrm{~s}^{-1}$ ) resulting in formation of the benzyl radical following homolytic cleavage of the peroxy $\mathrm{O}-\mathrm{O}$ bond allows the clear differentiation between modes of metal-mediated peroxide cleavage (Scheme 1).

The reactions of excess $\mathrm{MPPH}^{9}(5.21 \mathrm{mM})$ in the presence of either $\left[\mathrm{Fe}^{2+}, \mathrm{Fe}^{2+}\right], 1,\left[\mathrm{Fe}^{3+}, \mathrm{Fe}^{3+}\right], 2$, or $\mu-\mathrm{oxo}-\left[\mathrm{Fe}^{3+}, \mathrm{Fe}^{3+}\right], 3$ ([complex] $=0.10 \mathrm{mM}$ ), were investigated under strict anaerobic conditions using $\mathrm{MeOH}$ as solvent. All iron complexes were stable under the reaction conditions in the absence of MPPH for over 12

3678 - J. AM. CHEM. SOC. 2003, 125, 3678-3679
Scheme 1

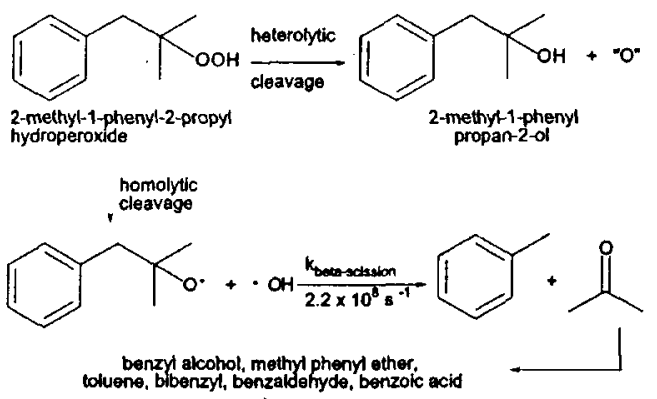

Table 1. Product Distributions for the Cleavage of MPPH by Iron Complexes

\begin{tabular}{|c|c|c|c|c|c|}
\hline \multirow[b]{2}{*}{ species } & \multicolumn{2}{|c|}{$\begin{array}{l}\text { products } \\
\text { helerolytic cleavage }\end{array}$} & \multicolumn{2}{|c|}{$\begin{array}{l}\text { products } \\
\text { homolytic cleavageac }\end{array}$} & \multirow{2}{*}{$\begin{array}{c}\text { mass } \\
\text { balance }\end{array}$} \\
\hline & $\%$ & T.N. & $\%$ & T.N. & \\
\hline $\begin{array}{l}{\left[\mathrm{Fe}^{2+}, \mathrm{Fe}^{2+}\right], 1} \\
{\left[\mathrm{Fe}^{3+}, \mathrm{Fe}^{3+}\right], 2} \\
\mu-\mathrm{oxo}-\left[\mathrm{Fe}^{3+}, \mathrm{Fe}^{3+}\right], 3\end{array}$ & $\begin{aligned} 85 & \pm 1 \\
0 & \pm 0 \\
0 & \pm 0\end{aligned}$ & $\begin{array}{c}44 \pm 1 \\
0 \\
0\end{array}$ & $\begin{array}{r}0 \pm 0 \\
37 \pm 1 \\
34 \pm 2\end{array}$ & $\begin{array}{l}0 \\
19 \pm 1 \\
17 \pm 1\end{array}$ & $\begin{array}{r}101 \pm 2 \\
99 \pm 1 \\
101 \pm 2\end{array}$ \\
\hline
\end{tabular}

all reactions were performed with an excess of peroxide (52:1 MPPH(5.21 mM):iron complex $(0.10 \mathrm{mM})$ ) under strict anaerobic conditions in $\mathrm{MeOH}$ for $6 \mathrm{~h}$. Turnover numbers are corrected for nonmetal-catalyzed products. ' ${ }^{6} 1$-Methyl-2-phenyl-propan-2-ol. ' Phenyl methyl ether, bibenzyl. benzyl alcohol and benzaldehyde were observed in a 50:10:7:1 ratio. Other possible products, including toluene and benzoic acid, were below levels of detection. ${ }^{d}$ Quantitative analyses were performed by gas chromatographic methods using chlorobenzene as internal standard.

hours. MPPH showed equivalent stability in the absence of metal complexes; GC analyses and iodometric titration ${ }^{10}$ showed the absence of either homolytic or heterolytic cleavage for a period of $15 \mathrm{~h}$. Parallel control reactions (absence of catalysts) were used to correct for nonmetal-mediated peroxide cleavage. Total mass balance of the parent peroxide and the various cleavage products at the end of $6 \mathrm{~h}$ was obtained by GC analyses and iodiometric titrations. The effect of iron core oxidation state on MPPH cleavage pathway is dramatically shown in Table 1 . After $6 \mathrm{~h}$ (room temperature), approximately $90 \%$ of the initial [MPPH] (45 turnovers) reacted with 1 by the heterolytic pathway to yield 2-methyl-1phenyl-propan-2-ol; any iron-induced homolytic cleavage products formed were below our limits of detection. These data directly contrast the results obtained with the $\left[\mathrm{Fe}^{3+}, \mathrm{Fe}^{3+}\right]$ complex 2 (19 turnovers) and with the $\mu$-oxo- $\left[\mathrm{Fe}^{3+}, \mathrm{Fe}^{3+}\right]$ complex 3 (17 turnovers), where only homolytic cleavage products (phenyl methyl ether, bibenzyl, benzyl alcohol) of MPPH were observed. Peroxide activity assays performed at the end of each reaction showed the appropriate concentration of unreacted MPPH. ${ }^{10} \mathrm{Free}^{\mathrm{Fe}}{ }^{2+}$ and $\mathrm{Fe}^{3+}$ ions supported only homolytic cleavage (22 and 31 turnovers, respectively) under equivalent conditions, suggesting that the electronic environment generated by the $\mathrm{H}_{2} \mathrm{Hbamb}{ }^{2-}$ ligand is important for heterolytic cleavage chemistry to occur. Neither free $\mathrm{H}_{4} \mathrm{Hbamb}$ nor 
COMMUNICATIONS

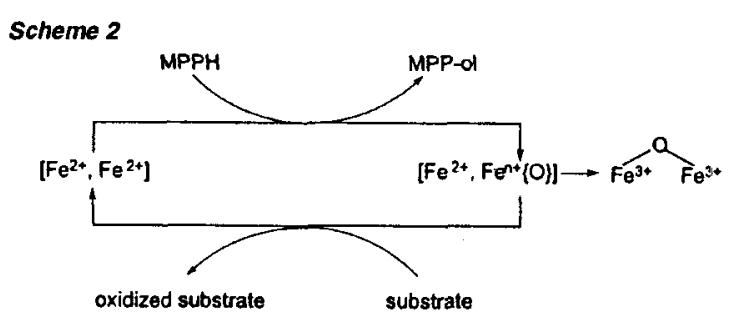

$\mathrm{Li}_{2}\left(\mathrm{H}_{2} \mathrm{Hbamb}\right)$ ligand catalyzed MPPH cleavage. The catalytic reaction of 1 with MPPH was facilitated by $\mathrm{MeOH}$, which reacted quantitatively with the iron-based intermediate to form formaldehyde during peroxide turnover. ${ }^{11}$ The absence of a suitable substrate (solvent) led to formation of diamagnetic $\mu$-oxo- $\left[\mathrm{Fe}^{3+}, \mathrm{Fe}^{3+}\right], 3$ (EPR silent, $\nu_{a s} \mathrm{Fe}-\mathrm{O}-\mathrm{Fe}=840 \mathrm{~cm}^{-1}$ ), resulting from collapse of the reactive intermediate formed by the 1:1 interaction of MPPH and the diferrous core of 1 .

The above data can be explained by the formal transfer of an oxygen atom obtained from the heterolytic cleavage of MPPH to a ferrous center in 1, resulting in a two-electron oxidation of the electronic structure of 1 (Scheme 2). The subsequent intermediate can be viewed as an $\left[\mathrm{Fe}^{2+}, \mathrm{Fe}^{4+}=0\right] \rightarrow\left[\mathrm{Fe}^{2+}, \mathrm{Fe}^{n+}\{0\}^{+}\right]$species where the latter electronic description is meant to convey the potential for unpaired electron density on either the diamide or terminal oxo ligands. This intermediate may also collapse to a $\mu$-oxo- $\left[\mathrm{Fe}^{3+}, \mathrm{Fe}^{3+}\right]$ dimer which in itself is inert as an oxygen atom transfer catalyst. The data also suggest that while the ligand system is capable of stabilizing an $\mathrm{Fe}^{4+}$ intermediate species generated from heterolysis of the $\mathrm{Fe}^{2+}-\mathrm{OOR}$ species, it is unable to afford the $\mathrm{Fe}^{\mathrm{st}}$ species that would result from heterolysis at an $\mathrm{Fe}^{3+}-\mathrm{OOR}$ center.

Catalytic oxygen atom transfer reactions utilizing $\mathrm{PhSMe}$ and cyclohexane $(\mathrm{C}-\mathrm{H} \text { bond strength } \sim 95 \mathrm{kcal} / \mathrm{mol})^{12}$ as substrates are summarized in Table 2 . In each case, phenyl methyl sulfoxide (500 turnovers) and cyclohexanol (230 turnovers) were initially formed prior to the production of phenyl methyl sulfone (11 turnovers) and cyclohexanone (5 turnovers). Parallel control reactions showed negligible product formation ( $\leq 10$ turnovers) in the absence of catalyst, suggesting the primary role of an iron-based oxidant. Tight coupling between MPPH $\mathrm{O}-\mathrm{O}$ bond cleavage and the oxygen atom transfer process is demonstrated by quantitatively comparing the levels of 2-methyl-1-phenylpropan-2-ol with equivalents of product (sulfoxide or alcohol). The results indicate the bigh efficiency of MPPH utilization $(99 \pm 1 \%$ ) and that only heterolytic cleavage of MPPH occurs during catalysis. The data in Table 2 also establish that the ferrous centers in 1 return to their reduced states at the end of each cycle (Scheme 2). Adventitious oxidation of 1 or collapse of the intermediate to the $\mu$-oxo- $\left[\mathrm{Fe}^{3+}, \mathrm{Fe}^{3+}\right]$ dimer would result in an iron complex population that would facilitate homolytic cleavage of the alkyl peroxide $0-0$ bond, leading to detection of MPPH products based on the reactivity of the benzyl radical. The observed absence of these species only allows for a lower bound for the partitioning of productive versus nonproductive processes $(\geq 500: 1)$ during catalysis.

These data demonstrate the ability of reduced binuclear 1 to act as an efficient catalyst for the heterolytic cleavage of MPPH and
Table 2. Product Distributions of Catalytic Atom Transfer Reactions

\begin{tabular}{lcccc}
\hline & $\begin{array}{c}\text { equivalents } \\
\text { substrate" }\end{array}$ & \multicolumn{2}{c}{ equivalents products } & mass \\
\cline { 3 - 4 } sutioxidelatcohol & sulfone/akelone & malance (\%) \\
\hline thioanisole & 524 & $500 \pm 13$ & $11 \pm 2$ & $98 \pm 2$ \\
cyclohexane & 239 & $230 \pm 30$ & $5 \pm 1$ & $97 \pm 3$ \\
\hline
\end{tabular}

- All reactions were run in $\mathrm{DMF} / \mathrm{CH}_{2} \mathrm{Cl}_{2}(30 / 70)$ which were freshly distilled and degassed several times prior to use (Fe:MPPH:Ph-S-Me 1:596:6011, Fe:MPPH:C6H12-1:600:2500); reaction time $=6 \mathrm{~h}$ ).

for subsequent oxygen atom transfer to substrate. Heterolytic cleavage of the peroxide argues against the possibility of freely diffusing radicals being responsible for the oxidative chemistry that is observed. This fulfills an essential requirement for modeling oxygenases, which proceed exclusively via a heterolytic pathway in order to avoid the formation of biologically damaging hydroxy radicals. Furthermore, the observed tight coupling between heterolytic cleavage of the alkyl peroxide and the transfer of an oxygen atom to an organic substrate (reaction efficiency $>99 \%$ ) models the chemistry exhibited at the active site of iron-based monooxygenases where one oxidized substrate is generated per equivalent of $\mathrm{O}_{2}$ consumed. Studies designed to define both the scope and mechanism of the substrate oxidation reactions are underway.

Acknowledgment. Financial support for this research was provided in part by the U.S. Department of Energy, Office of Basic Energy Sciences (ER14279) and by NIH (GM61208). We thank FMC Corporation for the generous gift of $70 \% \mathrm{H}_{2} \mathrm{O}_{2}$.

\section{References}

(1) Valentine, J. S. In Dioxygen Reactions; I. Bertini, H. B. G., Lippard, S. J., Valentine, J. S., Eds.; University Science Press: Mill Valley, CA, 1994 pp 253-313.

(2) Malmstrom, B. G. Annu. Rev. Biochem. 1982, 51, 21-59.

(3) Que, L. J.; Ho, R. Y. N. Chem. Rev. 1996, 96, 2607-2624.

(4) Wallar, B. J.; Lipscomb, J. D. Chem Rev. 1996, 96, 2625-2657.

(5) Kappock, T. J.; Caradonna, J. P. Chem. Rev. 1996, 96, 2659-2756.

(6) MacFaul, P. A.; Ingold, K. U.; Wayner, D. D. M.; Que, L., Jr. J. Am Chem. Soc. 1997, 119, 10594-10598. MacFaul, P. A.; Arends, i. W. C. E.; Ingold, K. U.; Wayner, D. D. M. J. Chem. Soc., Perkin Trans. 1997, 2, 135-145. Arends, I. W. C. E.; Ingold, K. U.; Wayner, D. D. M. J. Am. Chem. Soc. 1995, $117,4710-4711$.

(7) Abbreviations: H4Hbamb, 2,3-bis(2-hydroxybenzamido)2,3-dimethylbutane: $\left[\mathrm{Fe}^{2+}, \mathrm{Fe}^{2+}\right] \mathrm{Fe}_{2+}{ }^{2+}\left(\mathrm{H}_{2} \mathrm{Hb}\right.$ bamb $\left.b(\mathrm{~N}-\mathrm{MeIm})_{-} ; \mathrm{Fe}^{3+}, \mathrm{Fe}^{3+}\right],\left[\mathrm{Fe}^{2+3+}\left(\mathrm{H}_{2-}\right.\right.$ $\left.\left.\mathrm{Hbamb})_{2}(\mathrm{~N}-\mathrm{Melm})_{2}\right] \mathrm{(I}^{-}\right) ; \mu$-oxo- $\left[\mathrm{Fe}^{3+}, \mathrm{Fe}^{3+}\right], \mu-\mathrm{OxO}-\left[\mathrm{Fe}_{2}{ }^{3+}\left(\mathrm{H}_{2} \mathrm{Hbamb}_{2}(\mathrm{~N}-\right.\right.$ Melm) $)_{2}$.

(8) Mukerjee, S.; Stassinopoulos, A.; Caradonna, J. P. J. Am. Chem. Soc. 1997, 119, 8097-8098.

(9) MPPH was prepared according to literature procedures via the classical MPPH was prepared according to literature procedures via the classical
alcohol $/ \mathrm{H}_{2} \mathrm{O}_{2}$ route at $40^{\circ} \mathrm{C}$ using $70 \% \mathrm{H}_{2} \mathrm{O}_{2}$ (FMC Corporation). . $^{13}$ The

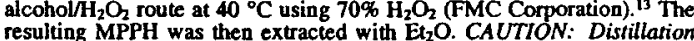
resulting MPPH was then extracted with $\mathrm{Et}_{2} \mathrm{O}$. CAUTTON: Distillation
of the MPPH/ether solution resuled in an explosion! This step was of the MPPH/her solution resuled in an explosion! This step was
replaced by solvent removal under a stream of $\mathrm{N}_{2}$. The crude peroxide replaced by solvent removal under a stream of $\mathrm{N}_{2}$. The crude peroxide
was recrystallized from $n$-pentane at $20^{\circ} \mathrm{C}$, affording pure crystalline was recrystallized from $n$-pentane at $20^{\circ} \mathrm{C}$, affording pure crystalline
MPPH in $>80 \%$ isolated yield. NMR and mass spectroscopic (parent ion MW: 166.2) characterizations gave reported results. Active MPPH levels, measured by iodiomertic titrations, showed $100 \%$ peroxide activity.

(10) Christian, G. D. Analytical Chemistry, 5th ed.; John Wiley and Sons: New York, 1994.

(11) Quantitative studies for formaldehyde production show $98 \pm 3 \%$ formation of oxidized solvent based on equivalents of 22-methyl-1-phenylpropan-2-
ol. Jacobsen, N. W. Dickinson, R. G. Anal. Chem. 1974, 46, 298-300.

(12) Gerald, K.; Cook, J. M. M. J. Am. Chem. Soc. 1995, 117, 7139-7156.

(13) Hiatt, R. R.; Strachen, W. M. J. J. Am. Chem. Soc. 1963, 2, 1803-1804. JA0286268 